\title{
Spot price modeling and the valuation of electricity forward contracts: The role of demand and capacity
}

\author{
Álvaro Cartea ${ }^{\mathrm{a}, *, 1}$, Pablo Villaplana ${ }^{\mathrm{b}, 2}$ \\ a Commodities Finance Centre, University of London, Birkbeck, UK \\ b Comisión Nacional de Energía, Spain
}

\section{A R T I C L E I N F O}

\section{Article history:}

Available online 30 April 2008

\section{JEL classification:}

C5

G00

G12

G13

Q4

Q41

\section{Keywords:}

Power prices

Demand

Capacity

Forward premium

Forward bias

Market price of capacity risk

Market price of demand risk

PJM

England and Wales

Nord pool

\begin{abstract}
A B S T R A C T
We propose a model where wholesale electricity prices are explained by two state variables: demand and capacity. We derive analytical expressions to price forward contracts and to calculate the forward premium. We apply our model to the PJM, England and Wales, and Nord Pool markets. Our empirical findings indicate that volatility of demand is seasonal and that the market price of demand risk is also seasonal and positive, both of which exert an upward (seasonal) pressure on the price of forward contracts. We assume that both volatility of capacity and the market price of capacity risk are constant and find that, depending on the market and period under study, it could either exert an upward or downward pressure on forward prices. In all markets we find that the forward premium exhibits a seasonal pattern. During the months of high volatility of demand, forward contracts trade at a premium. During months of low volatility of demand, forwards can either trade at a relatively small premium or, even in some cases, at a discount, i.e. they exhibit a negative forward premium.
\end{abstract}

\section{Introduction}

Although electricity is considered to be a commodity, its price behavior is strikingly different from that of any other commodity or more generally from that of any other asset. The most conspicuous features of its price dynamics are the presence of a seasonal trend and short-lived deviations or spikes with strong mean reversion, a unique characteristic of the power market. The latter behavior is a consequence of the complex dynamics of, and the interaction between, the demand and supply of a commodity which is either impossible or un-economical to store.

\footnotetext{
* Corresponding author.

E-mail addresses: a.cartea@bbk.ac.uk (Á. Cartea), pvc@cne.es (P. Villaplana).

1 Á. Cartea is thankful for the hospitality and generosity shown by the Finance Group at the Saïd Business School, Oxford, where part of this research was undertaken.

${ }^{2}$ P. Villaplana acknowledges financial support provided by Fundación Ramón Areces. The views expressed in this paper are the author's sole responsibility and do not reflect those of the Comisión Nacional de Energía, CNE.
}

This inability to store power is perhaps the pivotal reason for the extreme behavior of electricity's price dynamics. Unlike most commodities, once electricity is produced it must be consumed. When storing a commodity is feasible, mismatches between demand and supply can be partially met by either storing the good or by drawing from inventories. In this way, storage capabilities act as a buffer and have the effect of smoothing out price deviations from their expected seasonal trend. A clear example is gas, where storage levels follow a seasonal profile that reflects net demand or supply. Where demand outstrips supply, usually between the months of December-April, inventories are depleted; where supply exceeds demand storage facilities are replenished. However, contrary to the way inventories act against sharp price deviations in most commodities, the absence of storage in electricity markets amplifies the effects produced by mismatches between supply and demand.

Moreover, the adverse consequences of not being able to store power are exacerbated by the composition of the generation park of every market. There are two sides to this problem that must 
be considered. First, in most markets around the world, the vast majority of generation capacity is concentrated in a small number of companies that own generation plants. Therefore the actions or performance of just one player in the market may have an impact on equilibrium prices. Furthermore, due to the economies of scale in this market, investments come in large tranches, hence installed capacity increases in steps rather than in a gradual manner. The immediate implication is that power supply takes the form of a 'supply stack' since different plants come on line at different prices which, makes equilibrium prices very unstable around these step changes.

The second aspect that must be contemplated is that every generation park consists of a heterogeneous ensemble of plants where the main characteristic that differentiates them is the source employed to produce power and their cost function (marginal costs). For instance, the Scandinavian power market is dominated by hydro plants, but most of the time the marginal plants that determine equilibrium prices are coal, gas or oil-based. Similarly, in the England and Wales (E\&W) market gas and coal plants, representing around $60 \%$ of generation capacity, are usually the marginal entrants that set prices.

Nevertheless, the peculiarities of the supply side are not solely responsible for the exceptional behavior of power prices. Aggregate demand is highly inelastic and mainly dependent on weather and economic activity. Short-term unexpected demand variations are normally attributed to changes in weather, but on a longer time scale, the different seasons of the year, together with the economic cycle, also affect the seasonal trend that underlies aggregate demand.

The main contribution of this article is to introduce a general framework that analyzes how demand and capacity determine wholesale electricity prices. We propose a flexible model that allows different specifications both for the modeling of the state variables (demand and capacity) and for the relationship between state variables and electricity prices. Moreover, the specification of our model allows us to obtain closed-form solutions for forward prices which enables us to directly examine the dynamics of the forward premium. Finally, we exemplify the use of our model by analyzing the markets of PJM, E\&W and Nord Pool.

The rest of this article is structured as follows. In Section 2 we present an overview of previous work on the valuation of electricity derivatives. Section 3 analyzes the characteristics of the supply and demand of electricity. In Section 4 we propose the model for the electricity spot price as a function of demand and generation capacity. Further, in Section 5 we present the model under the risk-adjusted probability measure, derive valuation formulae for forward contracts and discuss the forward premium. Finally, Section 6 concludes.

\section{Models for the valuation of electricity derivatives}

Modeling power prices, and other financial instruments related to this market, is quite recent in the academic literature. For instance, although the subject matter was not the modeling of power prices but storable commodities, the work of Schwartz (1997) and Schwartz and Smith (2000) served as a platform for a number of articles that dealt with the valuation of electricity derivatives by proposing no-arbitrage models for the dynamics of wholesale electricity prices. For example, in the work of Lucia and Schwartz (2002) and Carte and Villaplana (2008) power prices are modeled according to non-observable state variables that account for the short-term movements and long-term trends in electricity prices. In particular, the former looks into the valuation of electricity futures contracts traded in the Nord Pool (Scandinavian market), and the latter introduces the possibility of jumps in the short-term process of the Schwartz and Smith (2000) model, derives valuation formulae for forward contracts and undertakes an empirical analysis of the PJM market. Similarly, Cartea and Figueroa (2005) present a mean-reverting jump-diffusion model of wholesale electricity prices and derive closed-form formulae for forward contracts and apply the model to the E\&W power market. Finally, Geman and Roncoroni (2006) focuses on the modeling of spot prices and apply their model to the PJM, ECAR and COB markets.

Alternatives to no-arbitrage models are the so-called equilibrium and hybrid models which, given the particular characteristics of electricity, explain price formation based on state variables that are mainly associated to supply and demand. This line of research has been pursued in Geman and Eydeland (1998); Pirrong and Jermakyan (1999); Pirrong and Jermakyan (2000); Bessembinder and Lemmon (2002); Longstaff and Wang (2004); Barlow (2002); Skantze et al. (2000) and Skantze and Ilic (2001) among others.

For example, Pirrong and Jermakyan (1999) and Pirrong and Jermakyan (2000) propose to model the equilibrium price as a function of two state variables, electricity demand and the futures price of the marginal fuel. Moreover, the authors consider that electricity prices should be an increasing and convex function of demand.

Bessembinder and Lemmon (2002) adopted an equilibrium perspective and explicitly modeled the economic determinants of the forward market. In their model, producers face marginal production costs that may increase steeply with output and aggregate demand is exogenous and stochastic. They show that the forward premium, defined as the forward minus the expected spot price, is positively (resp. negatively) related to the skewness (resp. variance) of the spot price. One of the key insights is that the risk of price spikes, due to sudden positive shocks in power demand, can have important effects on the size and the sign of the forward premium. In their equilibrium model, the resulting expression for spot prices is given by the following expression: $P=a(D / N)^{k-1}$, where $P$ is the electricity spot price, $D$ is the demand level, $N$ number of (symmetric) producers (generators), and $a$ and $k>2$ are constants. Note that assuming $N$ constant is equivalent to assuming that generation capacity is also known and fixed.

Longstaff and Wang (2004) focus on the question of how electricity forward prices are related to expected spot prices. Their goal is to provide an empirical analysis of the theoretical predictions presented in Bessembinder and Lemmon (2002). They find a significant forward premium in the PJM market which they consider as being the result of "the rationality and risk aversion of economic agents participating in the market". They point out that "total demand approaching or exceeding the physical limits of power generation" is an important economic risk (related also to quantity risk) and "the risk of price spikes as demand approaches system capacity is an extreme type of risk which may have important implications for the relation between spot and forward prices".

Therefore in those situations where the demand level is near the maximum capacity of the system, the behavior of electricity prices can be quite abrupt, since electricity must be generated by plants with higher marginal costs (convexity of the supply function). Furthermore, although Longstaff and Wang (2004) try to establish a relationship between the forward premium and the difference between maximum capacity and expected demand, they must assume (due to lack of data) that generating capacity is constant.

Furthermore, Barlow (2002); Skantze et al. (2000) and Skantze and Ilic (2001) have in common the fact that they impose a functional form for the relationship between price and two state variables: demand and a non-specified variable related to the supply side. For instance, Barlow (2002) proposed a non-linear Ornstein-Uhlenbeck process for the description of observed electricity prices. The author considered demand as 
the relevant state variable and modeled it as a mean-reverting process incorporating a non-constant mean given by a deterministic seasonal function. Skantze et al. (2000) and Skantze and Ilic, 2001 impose an exponential functional form between electricity spot prices and the state variables demand and a non-observable residual variable which is related to supply conditions.

In this article we model equilibrium electricity prices as a function of two observable state variables: demand and generation capacity. In this way we extend the work of Pirrong and Jermakyan (1999); Barlow (2002) and Bessembinder and Lemmon (2002) by considering the capacity of a system to generate electricity at any point in time as a random variable, in other words, capacity follows a stochastic process. Moreover, based on empirical observations and in line with Bessembinder and Lemmon (2002); we assume that electricity prices are increasing in demand and decreasing in capacity. Yet we propose a model flexible enough so that forward prices, a key building block in power markets, can be priced in closed-form, which also allows us to gain further insights into the characteristics of power markets by examining the forward premium for which we also obtain an analytical expression.

\section{Demand and effective generation capacity}

\subsection{Demand}

As mentioned above there are two key drivers that affect power demand: economic activity and weather conditions. On a broad level, the seasonal behavior of these drivers is passed onto the dynamics of power prices. For instance, the relationship between economic activity and electricity demand makes load (i.e. out-turn or realized demand) a seasonal variable too. Similarly, on short-time scales, electricity demand exhibits intra-day and intra-week seasonality with clearly discernible patterns. Within working days, for example, one can identify high demand (mornings and evenings) and low demand hours (generally from midnight to 6:00 am). And likewise, throughout the week, we may also observe that demand is higher during weekdays and lower during weekends and public holidays.

Weather, on the other hand, also influences electricity demand; temperature being one of the most influential factors. Extreme temperatures, high or low, induce a considerable use of air-conditioners or heating devices. As with cycles in economic activity, the marked seasonal patterns such as winters and summers are generally reflected in the seasonal levels of electricity prices. However, on short-time scales, electricity demand usually depends non-linearly on temperature (see Pardo et al. (2002)) which makes volatility of demand very sensitive to short-term weather variations; an effect which is exacerbated during periods of already high demand.

Therefore electricity demand may be modeled as a meanreverting process, where the mean is non-constant (seasonal) and with periods of high and low volatility. In order to take into account these features, we introduce several components in our model for the evolution demand. We assume

$$
\begin{aligned}
D_{t} & =g^{D}(t)+\chi_{t}^{D} \\
\mathrm{~d} \chi_{t}^{D} & =-k^{D} \chi_{t}^{D} \mathrm{~d} t+\sigma_{D}(t) \mathrm{d} Z_{t}^{D}
\end{aligned}
$$

where demand $D_{t}$ has a non-constant, deterministic trend given by the function $g^{D}(t)$, and $\chi_{t}^{D}$ is a mean-reverting process, with seasonal volatility captured by the term $\sigma_{D}(t)$ and $\mathrm{d} Z_{t}^{D}$ are the increments of a standard Brownian motion. ${ }^{3}$

From Figs. 1-3 it is straightforward to observe that the behavior of demand is different in each market. ${ }^{4}$ These differences are important in order to understand the behavior of spot prices (see Figs. 4-6), forward prices and forward premiums. For example, it is important to emphasize that demand levels in the PJM market exhibits the largest volatility and that the Nord Pool shows the largest kurtosis (see Table 1).

We employ daily demand data to estimate a discretized version of the demand model, (1) and (2), and obtain the parameter estimates by Maximum Likelihood. ${ }^{5}$ The discretized version of the demand model is given by

$D_{t}=g^{D}(t)+\chi_{t}^{D}$

$\chi_{t}^{D}=B \chi_{t-1}^{D}+\sigma_{D, t} \varepsilon_{t}$.

Here (4) is an autoregressive form of (2) where $B=1-k^{D}$, $\varepsilon_{t} \sim N(0,1)$ and

$\sigma_{D, t}=\sigma_{1}^{D}$ winter $_{t}+\sigma_{2}^{D}$ spring $_{t}+\sigma_{3}^{D}$ fall $_{t}+\sigma_{4}^{D}$ summer $_{t}$

is designed to capture the seasonal component of the time-dependent volatility by including quarterly dummies: fall $t_{t}$ takes the value 1 if the observation is on September, October or November and zero the rest of the months; spring $_{t}$ takes the value of 1 if the observation is March, April and May or zero in the rest of months; summer takes the value 1 if the observation is in June, July or August and zero the rest of the months; and winter ${ }_{t}$ is similarly defined. Finally, depending on the market, the seasonal component is given by

$g^{D}(t)=B_{0}+\sum_{j=2}^{12} M_{j} D_{j}^{M}+\sum_{j=2}^{y} Y_{j} D_{j}^{Y}$

or

$g^{D}(t)=B_{0}+\sum_{j=2}^{12} M_{j} D_{j}^{M}+C t$.

Here $D_{j}^{M}$ are the monthly dummies that take into account the existence of discrete changes in the annual mean level of the demand series; $D_{j}^{Y}$ are the yearly dummies ( $y$ varies depending on the market); $M_{j}$ and $Y_{j}$ are parameters; and $C$ is a parameter responsible for the linear trend in (7).

Table 2 shows parameter estimates for the demand model (3)(5) applied to three markets: PJM, E \&W and Nord Pool. Moreover, we used (6) for PJM and Nord Pool and (7) for E\&W. For comparison purposes we have estimated two different specifications for the volatility of demand in each market. The first specification assumes the volatility is constant $\sigma_{D}(t)=\sigma_{\text {const }}^{D}$ (results shown in columns with heading 'Const Vol') and the other assumes that volatility is seasonal as described in (5) (results shown under heading 'Seas Vol'). From the table we see that in all markets, the quarterly dum-

\footnotetext{
${ }^{3}$ We note that a simple extension to model (1) and (2) would consist of adding another factor to capture long-term shocks in the following way

$D_{t}=g^{D}(t)+\chi_{t}^{D}+\xi_{t}$

$\mathrm{d} \chi_{t}^{D}=-k^{D} \chi^{D} \mathrm{~d} t+\sigma_{D}(t) \mathrm{d} Z_{t}^{D}$

$\mathrm{d} \xi=\mu_{\xi} \mathrm{d} t+\sigma_{\xi} \mathrm{dZ}$

where $\mu_{\xi}$ and $\sigma_{\xi}$ are constant and $\mathrm{d} Z_{t}^{\xi}$ are the increments of a standard Brownian motion. With this specification the long-term equilibrium level $g^{D}(t)+\xi_{t}$ is not deterministic.

${ }^{4}$ In each market we use the day-ahead demand.

5 Since we are dealing with daily data, the discretization error is negligible, Melino (1994). The models have been estimated using the BHHH algorithm.
} 


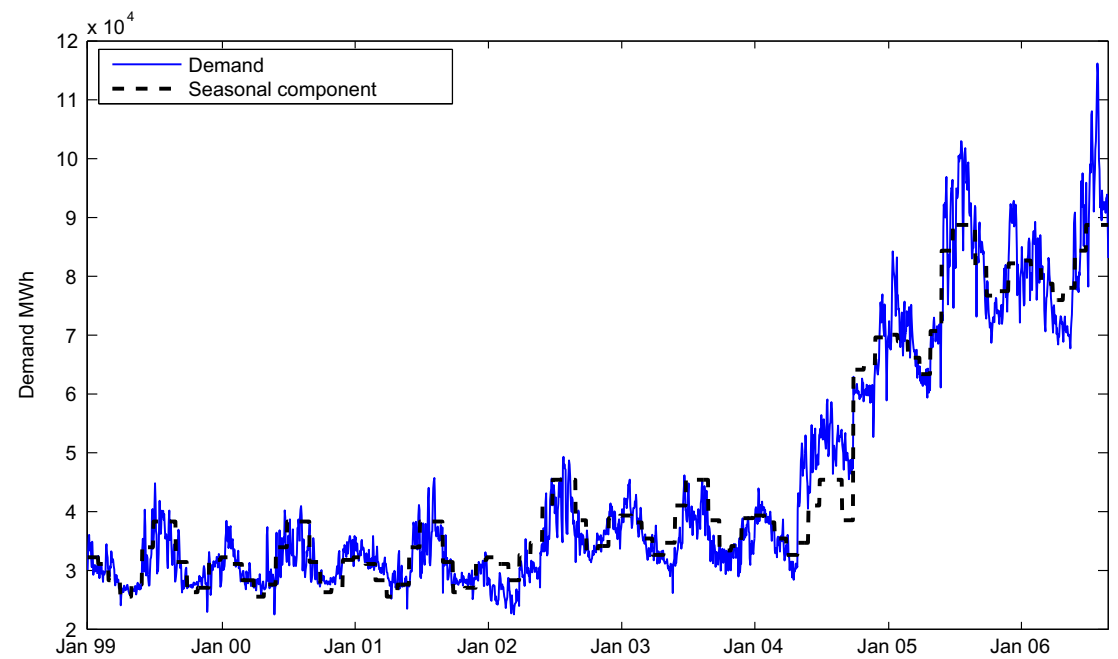

Fig. 1. PJM demand and estimated seasonal component $g^{D}(t)$ over the period January 1999-August 2006.

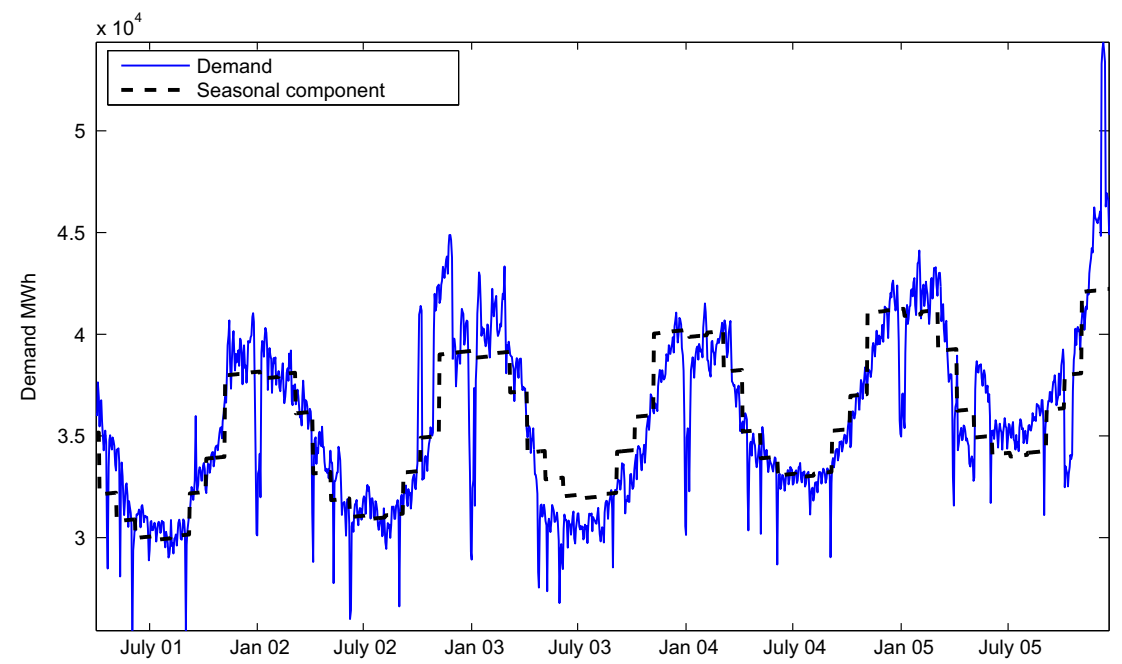

Fig. 2. E\&W demand and estimated seasonal component $g^{D}(t)$ over the period March 2001-March 2006.

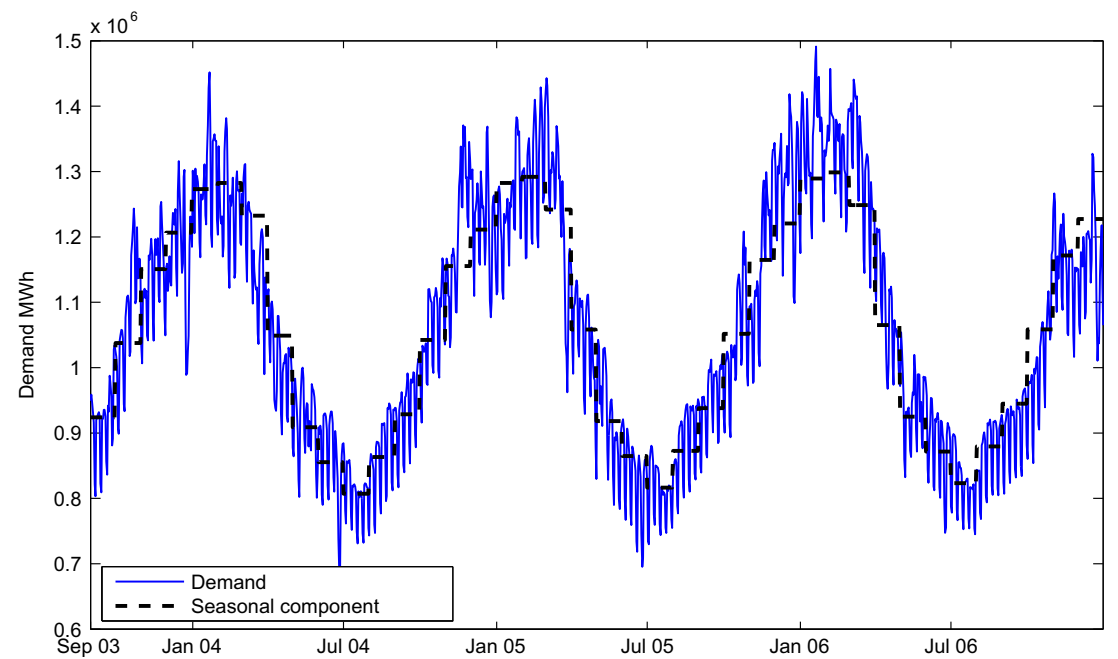

Fig. 3. Nord Pool demand and estimated seasonal component $g^{D}(t)$ over the period September 2003-December 2006. 
Table 1

Statistics for power prices and demand

\begin{tabular}{|c|c|c|c|c|c|c|c|c|c|c|c|c|}
\hline & \multicolumn{4}{|l|}{ PJM } & \multicolumn{4}{|l|}{ E\&W } & \multicolumn{4}{|l|}{ Nord Pool } \\
\hline & $D_{t}$ & $D_{t}-D_{t-1}$ & $\ln D_{t}$ & $\ln \left(D_{t} / D_{t-1}\right)$ & $D_{t}$ & $D_{t}-D_{t-1}$ & $\ln D_{t}$ & $\ln \left(D_{t} / D_{t-1}\right)$ & $D_{t}$ & $D_{t}-D_{t-1}$ & $\ln D_{t}$ & $\ln \left(D_{t} / D_{t-1}\right)$ \\
\hline Num. Obs. & 2800 & 2799 & 2800 & 2799 & 1240 & 1239 & 1240 & 1239 & 2922 & 2921 & 2922 & 2991 \\
\hline Mean & 43775.21 & 18.94 & 10.60 & 0.00 & 36433.53 & 8.58 & 10.50 & 0.00 & 14515.38 & 8.43 & 9.50 & 0.00 \\
\hline Median & 34612.00 & -149.00 & 10.45 & 0.00 & 35715.00 & 50.00 & 10.48 & 0.00 & 13142.25 & -50.00 & 9.48 & 0.00 \\
\hline Min & 20699.00 & -16311.00 & 9.94 & -0.28 & 25434.00 & -8309.00 & 10.14 & -0.23 & 5624.80 & -3819.40 & 8.63 & -0.18 \\
\hline Max & 116187.00 & 16270.00 & 11.66 & 0.37 & 54354.00 & 8320.00 & 10.90 & 0.19 & 39227.80 & 6137.60 & 10.58 & 0.34 \\
\hline Std & 20415.01 & 3129.13 & 0.41 & 0.07 & 4654.99 & 1217.21 & 0.13 & 0.03 & 6380.82 & 826.26 & 0.39 & 0.05 \\
\hline Skew & 1.21 & 0.41 & 0.79 & 0.49 & 0.60 & -0.32 & 0.30 & -0.29 & 1.36 & 1.03 & 0.54 & 0.81 \\
\hline \multirow[t]{2}{*}{ Kurtosis } & 0.23 & 2.85 & -0.67 & 1.39 & 0.08 & 10.42 & -0.39 & 9.91 & 1.47 & 6.18 & -0.40 & 2.38 \\
\hline & $P_{t}$ & $P_{t}-P_{t-1}$ & $\ln P_{t}$ & $\ln \left(P_{t} / P_{t-1}\right)$ & $P_{t}$ & $P_{t}-P_{t-1}$ & $\ln P_{t}$ & $\ln \left(P_{t} / P_{t-1}\right)$ & $P_{t}$ & $P_{t}-P_{t-1}$ & $\ln P_{t}$ & $\ln \left(P_{t} / P_{t-1}\right)$ \\
\hline Num. Obs. & 2800 & 2799 & 2800 & 2799 & 1240 & 1239 & 1240 & 1239 & 2922 & 2921 & 2922 & 2991 \\
\hline Mean & 37.48 & 0.01 & 3.50 & 0.00 & 24.87 & 0.02 & 3.10 & 0.00 & 27.47 & 0.00 & 3.19 & 0.00 \\
\hline Median & 33.69 & -0.41 & 3.52 & -0.01 & 20.37 & 0.00 & 3.01 & 0.00 & 26.21 & -0.14 & 3.27 & -0.01 \\
\hline Min & 8.19 & -368.00 & 2.10 & -2.61 & 10.39 & -86.27 & 2.34 & -1.52 & 3.89 & -32.28 & 1.36 & -0.77 \\
\hline Max & 397.34 & 251.18 & 5.98 & 2.78 & 183.32 & 139.40 & 5.21 & 1.77 & 114.61 & 53.72 & 4.74 & 1.19 \\
\hline Std & 22.93 & 16.22 & 0.48 & 0.27 & 14.83 & 7.98 & 0.44 & 0.18 & 14.39 & 2.70 & 0.51 & 0.10 \\
\hline Skew & 4.76 & -2.29 & 0.32 & 0.24 & 3.28 & 3.89 & 1.11 & 0.89 & 1.59 & 2.62 & -0.20 & 1.72 \\
\hline Kurtosis & 46.60 & 167.20 & 0.60 & 13.37 & 17.75 & 108.60 & 1.32 & 16.95 & 4.46 & 82.69 & 0.11 & 26.53 \\
\hline
\end{tabular}

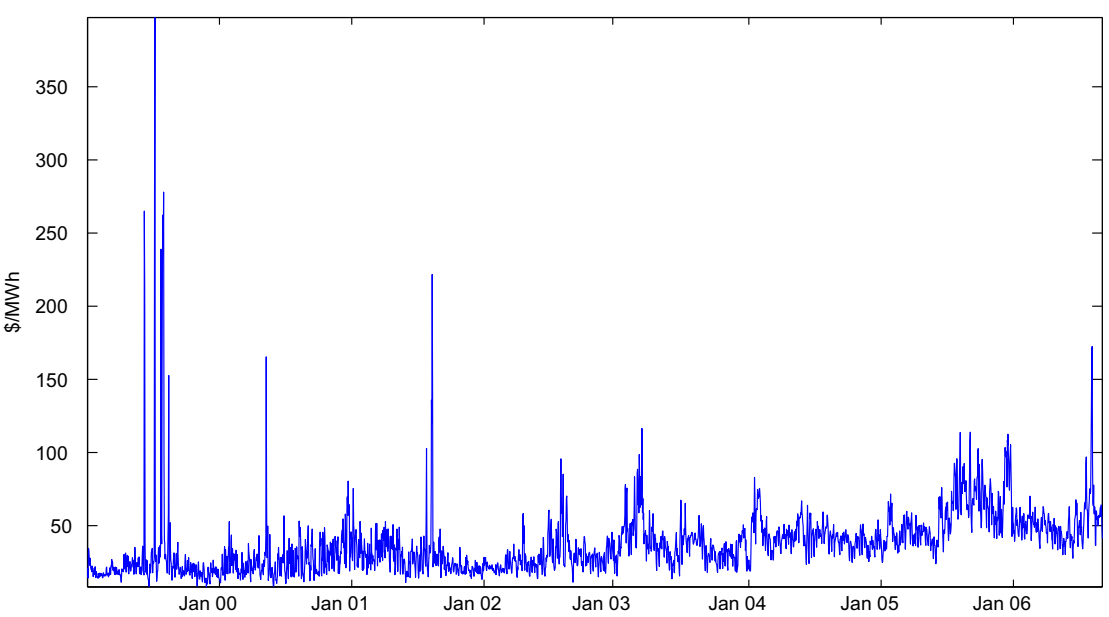

Fig. 4. PJM spot prices over the period January 1999-August 2006.

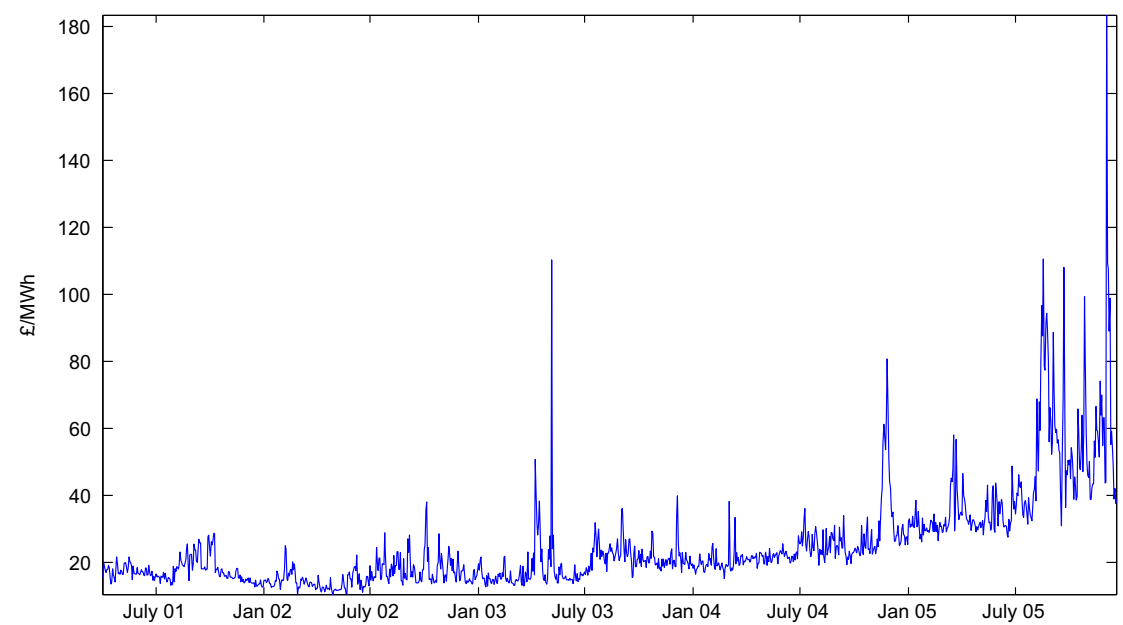

Fig. 5. E\&W spot prices over the period March 2001-March 2006. 


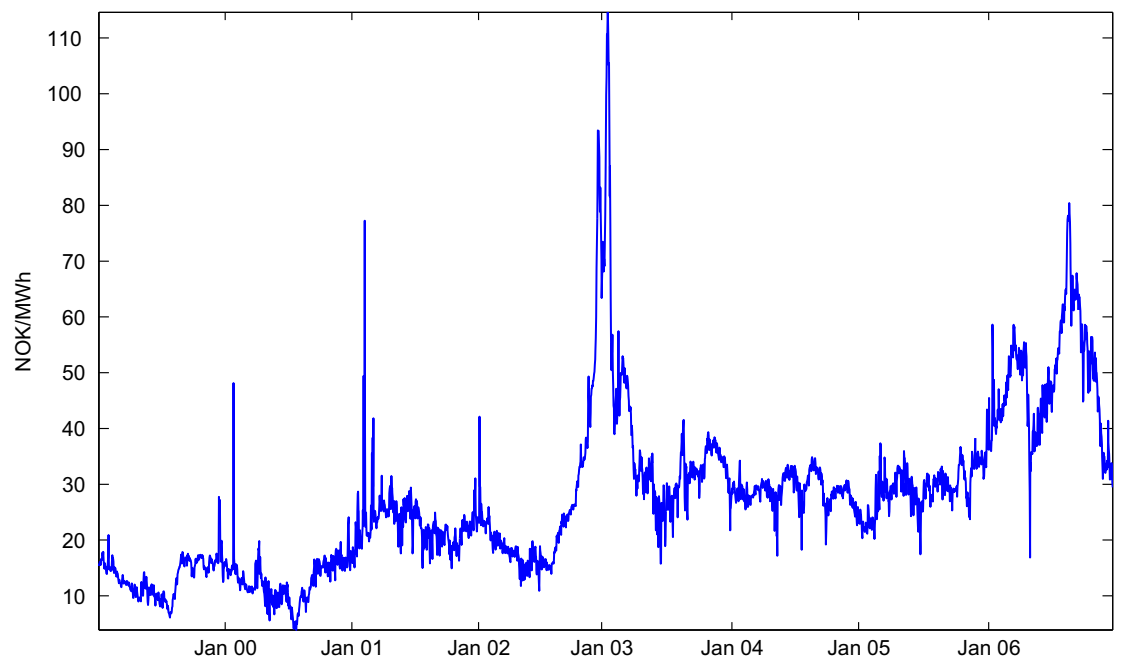

Fig. 6. Nord Pool spot prices over the period January 1999-December 2006.

Table 2

Parameter estimates for demand in PJM, E\&W and Nord Pool

\begin{tabular}{|c|c|c|c|c|c|c|c|c|c|c|c|c|}
\hline \multirow[b]{3}{*}{$B_{0}$} & \multicolumn{4}{|l|}{ PJM } & \multicolumn{4}{|l|}{ E\&W } & \multicolumn{4}{|l|}{ Nord Pool } \\
\hline & \multicolumn{2}{|l|}{ Const Vol. } & \multicolumn{2}{|l|}{ Seas Vol. } & \multicolumn{2}{|l|}{ Const Vol. } & \multicolumn{2}{|l|}{ Seas Vol. } & \multicolumn{2}{|l|}{ Const Vol. } & \multicolumn{2}{|l|}{ Seas Vol. } \\
\hline & 32116.15 & 62.05 & 32253.96 & 91.70 & 37131.58 & 154.72 & 37024.91 & 103.14 & 1267358.28 & 96.31 & 1268589.72 & 84.41 \\
\hline$M_{2}$ & -1079.54 & -1.43 & -1154.57 & -2.49 & 319.85 & 0.69 & 126.86 & 0.17 & 10234.39 & 0.81 & 9316.71 & 0.61 \\
\hline$M_{3}$ & -3874.12 & -4.96 & -3916.81 & -7.74 & -1819.47 & -5.32 & -1417.90 & -4.14 & -40723.80 & -3.65 & -40631.19 & -3.11 \\
\hline$M_{4}$ & -6455.70 & -7.89 & -6700.07 & -12.33 & -4884.96 & -15.89 & -4913.86 & -11.85 & -223557.88 & -18.00 & -224221.86 & -15.69 \\
\hline$M_{5}$ & -4627.65 & -7.21 & -4640.05 & -10.63 & -6315.90 & -22.56 & -6313.21 & -16.03 & -358245.29 & -25.64 & -364414.32 & -23.49 \\
\hline$M_{6}$ & 1548.45 & 2.62 & 1692.55 & 2.74 & -7200.07 & -17.01 & -7231.53 & -19.57 & -416490.37 & -31.36 & -417859.21 & -34.25 \\
\hline$M_{7}$ & 5840.82 & 10.12 & 6074.61 & 10.17 & -7525.10 & -12.85 & -7418.93 & -18.75 & -463264.87 & -26.71 & -466017.54 & -33.56 \\
\hline$M_{8}$ & 5990.73 & 9.91 & 6065.91 & 9.50 & -7205.93 & -19.92 & -7319.21 & -20.35 & -406970.33 & -28.02 & -409953.25 & -32.06 \\
\hline$M_{9}$ & -909.60 & -1.42 & -811.73 & -1.88 & -5249.88 & -14.54 & -5299.99 & -11.36 & -343623.05 & -25.39 & -344530.58 & -22.83 \\
\hline$M_{10}$ & -6099.74 & -6.85 & -5952.42 & -10.55 & -3639.70 & -13.31 & -3670.37 & -9.46 & -228811.93 & -20.58 & -230903.21 & -17.98 \\
\hline$M_{11}$ & -5214.99 & -6.19 & -5192.79 & -9.48 & 318.03 & 1.11 & 331.71 & 0.83 & -117514.59 & -10.55 & -117801.93 & -9.19 \\
\hline$M_{12}$ & -417.11 & -0.59 & -461.33 & -1.09 & 309.30 & 1.38 & 353.37 & 0.93 & -61875.93 & -5.74 & -62036.10 & -4.76 \\
\hline$C$ & & & & & 3.72 & 17.45 & 3.93 & 20.65 & & & & \\
\hline$Y_{2}$ & 7179.39 & 19.24 & 7091.29 & 20.95 & & & & & & & & \\
\hline$Y_{3}$ & 37256.96 & 71.44 & 37828.30 & 91.80 & & & & & & & & \\
\hline$Y_{4}$ & 41496.42 & 68.57 & 43084.11 & 45.44 & & & & & 3857.12 & 0.35 & 4573.77 & 0.39 \\
\hline$Y_{5}$ & 51677.70 & 143.86 & 50417.87 & 150.02 & & & & & 16966.61 & 1.56 & 13930.77 & 1.19 \\
\hline$Y_{6}$ & & & & & & & & & 22131.24 & 2.00 & 20767.42 & 1.75 \\
\hline$B$ & 0.67 & 85.73 & 0.73 & 55.88 & 0.67 & 44.18 & 0.65 & 34.74 & 0.82 & 48.91 & 0.82 & 45.58 \\
\hline$\sigma_{\text {const }}^{D}$ & 3433.87 & 97.96 & & & 1582.91 & 87.37 & & & 55524.17 & 48.95 & & \\
\hline$\sigma_{1}^{D}$ & & & 2630.69 & 33.45 & & & 2066.98 & 42.96 & & & 61361.61 & 22.53 \\
\hline$\sigma_{2}^{D}$ & & & 54.48 & 0.53 & & & -453.75 & -6.06 & & & -3247.50 & -0.85 \\
\hline$\sigma_{3}^{D}$ & & & 94.92 & 0.83 & & & -451.93 & -6.22 & & & -4476.56 & -1.31 \\
\hline$\sigma_{4}^{D}$ & & & 1922.57 & 12.49 & & & -1085.51 & -19.99 & & & -18622.78 & -5.46 \\
\hline LL & -19128.02 & & -18880.93 & & -10918.53 & & -10833.48 & & -14986.35 & & -14968.35 & \\
\hline SC & 38392.86 & & 37921.48 & & 21943.92 & & 21795.19 & & 30094.75 & & 30078.73 & \\
\hline
\end{tabular}

The first column for each market assumes that volatility $\sigma_{D}(t)$ is constant and the second column assumes volatility varies across seasons according to (5). Note that $\sigma_{D}(t)$ for winter is given by $\sigma_{1}^{D}$, for spring is $\sigma_{1}^{D}+\sigma_{2}^{D}$, fall is $\sigma_{1}^{D}+\sigma_{3}^{D}$ and summer is $\sigma_{1}^{D}+\sigma_{4}^{D}$. LL: Log-likelihood and SC: Schwarz Criterion.

mies of the seasonal volatility specification are significant, moreover, according to the Schwarz Criterion, the seasonal volatility model is the preferred one. Finally, we have computed a LR test to check the difference between the restricted model (constant volatility model) and the unrestricted one (seasonal volatility specification), where we find that in the three markets the null hypothesis is clearly rejected at $1 \%$ significant levels.

It is interesting to mention the relationship between the level $g^{D}(t)$ of the demand series and the seasonal pattern in the volatility of the series. For example, Fig. 2 shows demand in E\&W over the period March 2001 to March 2006. Here we can observe that periods of high demand, i.e. high levels in $g^{D}(t)$, occur during the months of August through December. At the same time we ob- serve from Table 2 that volatility $\sigma_{D}(t)$ is also higher during the summer and fall seasons (i.e. June-November) coinciding with the times when $g^{D}(t)$ is already high. This feature, which is broadly present across the three different markets under study, will have interesting consequences. First, a straightforward effect is that across seasons when demand levels and volatility of demand are high, wholesale power prices will also, ceteris paribus, be high and volatile. Second, we can expect forward prices and the forward premium to reflect a seasonal pattern as a result of seasonality in the volatility of demand. We will me more precise about this last point in Section 4 when we present a model for power prices and in Section 5 where we study the forward premium. 


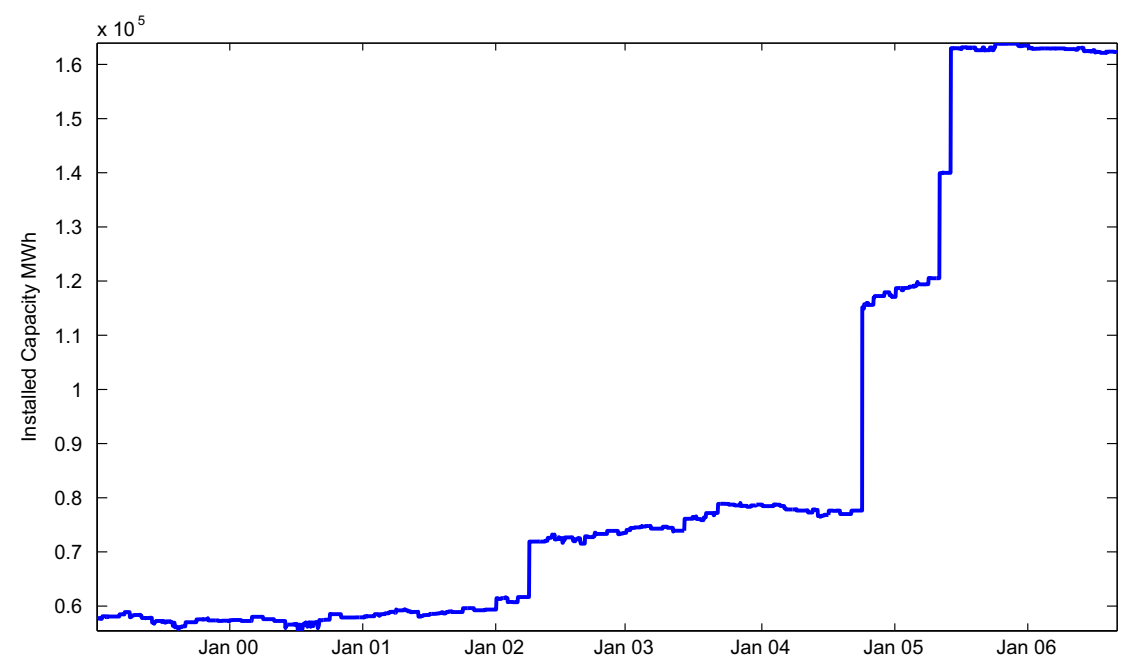

Fig. 7. PJM installed capacity over the period January 1999-August 2006.

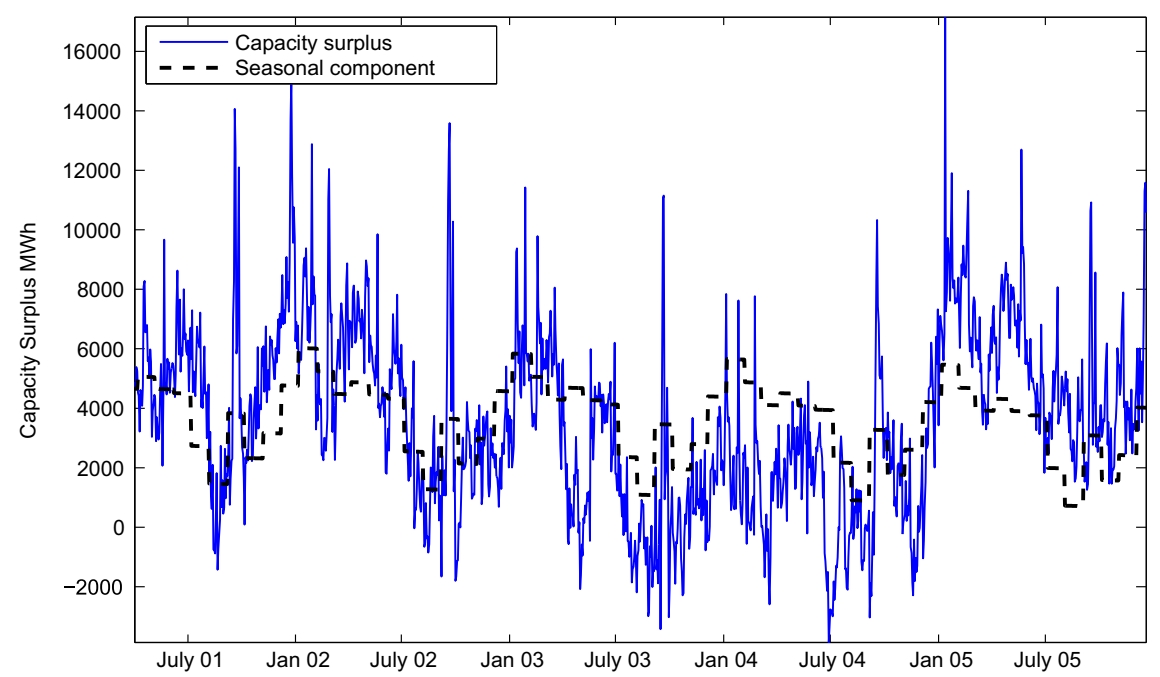

Fig. 8. E\&W capacity surplus and estimated seasonal component $g^{\complement}(t)$ over the period March 2001-March 2006.

\subsection{Generation capacity}

The inclusion of demand as a state variable is as important as the inclusion of effective generation capacity to explain the dynamics of spot or forward prices. The former accounts for the dynamics of aggregate demand and the latter accounts for the dynamics of the supply stack, yet it is the interaction between the two at every point in time (for example half-hour slots) what determines equilibrium market prices.

There are different definitions of capacity. One working definition of capacity is the maximum level of energy that can be produced at a point in time. In an ideal situation this figure should incorporate all generation that can be made available should the system operator call upon it. Hence, planned maintenance or other circumstances that reduce or increase the ability to generate power should already be accounted for when capacity is reported (see Cartea et al. (2007)).

One level of difficulty we face stems from the fact that not all markets are the same and that publicly available information also differs across them. For example, in the Nord Pool market it is relatively straightforward to obtain figures for reservoir levels, but capacity derived from other generation sources is not readily available. Therefore, when looking at the Scandinavian market we will use hydro reservoir as a proxy for total capacity. In the E\&W market, information on capacity (surplus) is made public by the National Grid Company (NGC). Finally, for the PJM market we use installed capacity. ${ }^{6}$

Figs. 7-9 show the proxies we use for generation capacity for the three markets we study. For instance, Fig. 7 shows installed capacity in the PJM market over the period January 1999-August 2006; Fig. 8 shows E\&W daily observations of capacity surplus over the period March 2001-March 2006; and Fig. 9 shows reservoir levels for the Nord Pool over the period January 1999-December 2006. Although the information we have relating to capacity differs across markets, it is clear from the figures that capacity cannot be considered a deterministic variable, instead, capacity must be considered as a state variable that exhibits two main characteristics. First, a predictable component since some of the fluctuations on

\footnotetext{
${ }^{6}$ Information for Nord Pool is obtained from www.nordpool.com; for E\&W is obtained from www.bmreports.com where we use the surplus variable SLPD; and for PJM from www.pjm.com.
} 


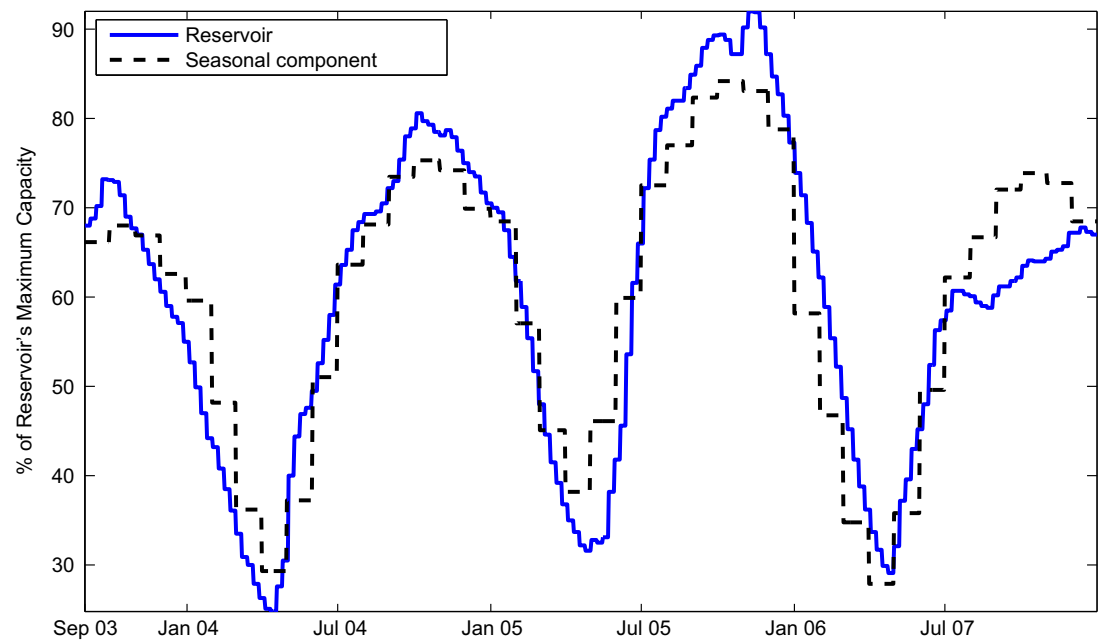

Fig. 9. Nord Pool capacity in terms of percentage of maximum reservoir capacity and estimated seasonal component $g^{\complement}(t)$ over the period September $2003-$ December 2006 .

generation capacity may be known in advance by market participants (for instance because of the existence of seasonality and/or planned outages). Second, short-lived deviations that are considered random shocks to the expected available capacity in the market.

We note that although reductions in available capacity are planned, and may be known by market participants, they have also been the cause of some of the jumps observed in price series. As an example, Krapels (2000) shows how the increase in prices in the New England market during 7-8 June 1999, was due to a combination of a known reduction in available capacity plus an unexpected increase in demand which could not be met because power plants could not be ramped up in time. Another example is Nord Pool where during the last months of 2002 and the beginning of 2003 the level of hydro reservoirs was at a historical low, and consequently, spot and forward prices underwent a sharp increase.

Kollberg et al. (1999) present further examples of how important the relationship between generation capacity and levels of forward prices in Nord Pool is: “... a shock that affected futures prices at Nord Pool was the decision by the Swedish government to close down one nuclear reactor at Barsebäck. At a time when the supply of electricity was already regarded as constrained in the Nordic region, this decision to cut production resources even further made the market react in a powerful way. Suddenly, there was a shift in all forward and futures contracts with maturity after the closing date". Therefore, fluctuations in price levels or short-lived price spikes are not caused by abrupt changes in demand alone, but also, possibly contributing on an equal footing, by changes in generation capacity.

Therefore, given the characteristics of the variable capacity we propose the following model for capacity:

$C_{t}=g^{C}(t)+\chi_{t}^{C}$

$\mathrm{d} \chi_{t}^{C}=-k^{C} \chi_{t}^{C} \mathrm{~d} t+\sigma_{C}(t) \mathrm{d} Z_{t}^{C}$.

Here $g^{C}(t)$ represents a deterministic seasonal component present in capacity and $\chi_{t}^{c}$ is a mean-reverting process with speed of reversion

\footnotetext{
${ }^{7}$ As in the demand model above we could also add another factor to account for long-term stochastic changes in the capacity levels. Furthermore, depending on the particular market under consideration, it could be desirable to add jumps in the dynamics of the short-term shocks $\chi_{t}^{c}$ to account for sudden unexpected changes in available capacity that cannot be captured by diffusive shocks.
}

$k^{C}$, volatility captured by $\sigma_{C}(t)$ and $\mathrm{d} Z_{t}^{C}$ are the increments of a standard Brownian motion. ${ }^{7}$

In order to estimate empirically the parameters of the model given by Eqs. (8) and (9) we use a discretized version of the model similar to the one used in the demand case. Depending on the market, we use different specifications for the seasonal component. For instance, in Nord Pool we modeled $g^{C}(t)$ as

$g^{C}(t)=B_{0}+\sum_{j=2}^{12} M_{j} D_{j}^{M}+\sum_{j=2}^{y} Y_{j} D_{j}^{Y}$

and in $\mathrm{E} \& W$ we used

$g^{C}(t)=B_{0}+\sum_{j=2}^{12} M_{j} D_{j}^{M}+C t$

where the dummies and parameters have the same interpretation as in the seasonal component for demand. For example, in specification (10), monthly and annual dummies are included in order to capture the changes on the level of the capacity variable for the different months of the year and for the different years.

For PJM we used a different approach due to the nature of the data we have for capacity. For example, from Fig. 7 we observe the existence of important discrete and permanent changes in the PJM capacity variable mainly as a consequence of a planned expansion of the PJM market (see FERC (2002)). Therefore the deterministic trend $g^{C}(t)$ is calculated as the mean of the monthly available capacity and the mean-reverting component $\chi_{t}^{c}$ is given by the difference between our proxy for capacity and the monthly means.

In the case of the PJM market we estimate $k^{C}$ and $\sigma_{\mathrm{C}}(t)$, employing autoregressive of order 1 model. In all markets we assumed that the volatility coefficient in (9) is constant, i.e. $\sigma_{C}(t)=\sigma^{C}$. The estimation results for PJM are $B=0.70$ (recall that $B=1-k^{C}$ ) and $\sigma^{C}=107.13$. The results for E\&W and Nord Pool are reported in Table 3.

\section{The model: the relationship between spot prices and state variables}

Based on empirical evidence we know spot prices should be increasing in demand and decreasing in capacity. Therefore, we may specify a generic function $\varphi(\cdot)$ such that wholesale power prices are given by $P_{t}=\varphi\left(D_{t}, C_{t}\right)$ and require $\partial \varphi / \partial D>0$ and $\partial \varphi /$ $\partial C<0$. 
Table 3

Parameter estimates for capacity in E\&W and Nord Pool

\begin{tabular}{|c|c|c|c|c|}
\hline & \multicolumn{2}{|l|}{ E\&W } & \multicolumn{2}{|l|}{ Nord Pool } \\
\hline & Const. Vol. & $t$-stat & Const. Vol. & $t$-stat \\
\hline$B_{0}$ & 6166.75 & 18.21 & 52.30 & 42.34 \\
\hline B & 0.63 & 32.18 & 0.85 & 60.16 \\
\hline$\sigma^{c}$ & 2056.30 & 58.73 & 3.88 & 39.17 \\
\hline C & -0.71 & -2.54 & & \\
\hline$M_{2}$ & -762.91 & -1.86 & -11.42 & -18.67 \\
\hline$M_{3}$ & -1508.77 & -3.04 & -23.39 & -32.69 \\
\hline$M_{4}$ & -1100.47 & -2.46 & -30.28 & -29.00 \\
\hline$M_{5}$ & -1498.00 & -3.90 & -22.36 & -30.16 \\
\hline$M_{6}$ & -1623.46 & -3.30 & -8.57 & -10.83 \\
\hline$M_{7}$ & -3381.43 & -7.91 & 4.03 & 4.41 \\
\hline$M_{8}$ & -4635.72 & -9.37 & 8.52 & 8.62 \\
\hline$M_{9}$ & -2248.21 & -6.54 & 13.86 & 16.78 \\
\hline$M_{10}$ & -3742.38 & -7.92 & 15.71 & 17.88 \\
\hline$M_{11}$ & -2885.80 & -6.11 & 14.60 & 16.34 \\
\hline$M_{12}$ & -1270.50 & -3.34 & 10.30 & 11.30 \\
\hline$Y_{4}$ & & & 7.30 & 5.84 \\
\hline$Y_{5}$ & & & 16.18 & 13.18 \\
\hline$Y_{6}$ & & & 5.87 & 4.91 \\
\hline LL & -1180.92 & & -3366.42 & \\
\hline
\end{tabular}

In addition to requiring $\varphi(\cdot, \cdot)$ to be increasing in demand and decreasing in capacity, we look for plausible functional forms so that forward prices can be expressed in closed-form. Hence, we propose the following model:

$P_{t}=\beta e^{\gamma C_{t}+\alpha D_{t}}, \quad \alpha>0, \gamma<0, \beta>0$,

where

$$
\begin{aligned}
D_{t} & =g^{D}(t)+\chi_{t}^{D} \\
\mathrm{~d} \chi_{t}^{D} & =-k^{D} \chi_{t}^{D} \mathrm{~d} t+\sigma_{D}(t) \mathrm{d} Z_{t}^{D}, \\
C_{t} & =g^{C}(t)+\chi_{t}^{C} \\
\mathrm{~d} \chi_{t}^{C} & =-k^{C} \chi_{t}^{C} \mathrm{~d} t+\sigma^{C} \mathrm{~d} Z_{t}^{C},
\end{aligned}
$$

and the standard Brownian motions $Z_{t}^{D}$ and $Z_{t}^{C}$ are independent. Then, by applying the natural logarithm to (12), we can write

$\ln P_{t}=h(t)+\gamma \chi_{t}^{C}+\alpha \chi_{t}^{D}$

where $h(t)=\ln \beta+\gamma g^{C}(t)+\alpha g^{D}(t)$. Further, we will assume that the seasonal component $h(t)$ has the same form as (6).

Before presenting the model under the risk-neutral probability measure, and deriving valuation formulae for forwards, we present some preliminary evidence about the adequacy of the proposed specification.

For example, by letting $\alpha=0$, we can analyze a restricted version of model (12). One can show that in this "pure capacity" model the logarithm of the expected price is given by the following expression:

$\ln \mathbb{E}_{t}^{\mathscr{P}}\left[P_{T}\right]=\ln \beta+\gamma g^{\mathrm{C}}(T)+\gamma\left(\mathrm{e}^{-k^{C}(T-t)} \chi_{t}^{C}+\frac{1}{2} \int_{t}^{T} \mathrm{e}^{-2 k^{C}(T-s)}\left(\sigma^{C}\right)^{2} \mathrm{~d} s\right)$,

where $\mathbb{E}_{t}^{\mathscr{P}}$ is the expectation operator with respect to the statistical measure $\mathscr{P}$ with information up until time $t$. It must be noted that the parameter $\gamma<0$ implies that expected power prices are decreasing, ${ }^{8}$ at an increasing rate, in capacity. For example, if capacity goes down (resp. up) prices go up (resp. down). On the other hand, we can also check the effect of seasonal changes in capacity on the expected price. For instance, during months of high capacity, i.e. high $g^{C}(T)$, expected prices are relatively lower than months with low seasonal capacity. Similarly, it is straightforward to see that positive (resp. negative) short-term deviations $\chi_{t}^{c}$ exert a downward (resp. upward)

\footnotetext{
${ }^{8}$ Assuming that $g^{C}(T)+\left(\mathrm{e}^{-k^{C}(T-t)} \chi_{t}^{C}+\frac{1}{2} \int_{t}^{T} \mathrm{e}^{-2 k^{C}(T-s)}\left(\sigma^{C}\right)^{2} \mathrm{~d} s\right)>0$.
}

pressure on expected prices and that this pressure decays at an exponential rate given by the speed of mean reversion $k^{C}$.

To estimate the parameters $\alpha$ and $\gamma$ we follow two steps. First, we deseasonalize the demand and capacity series using the results from the models (1), (2), (8), and (9). Second, using the deseasonalized series for demand and capacity, $\chi_{t}^{D}$ and $\chi_{t}^{C}$, we estimate $h(t), \alpha$ and $\gamma$ in (14) by Maximum Likelihood and report the results in Table 4. For example, we can see that for all markets the parameters $\alpha$ and $\gamma$ possess the correct sign and are statistically significant.

\section{Valuation of futures contracts}

In order to value derivatives contracts we have to express model (12) under a risk-neutral probability measure. In line with the literature on commodities, we incorporate the price of risk for the different sources of uncertainty in the same way as in, for example, Schwartz (1997) and Cartea and Figueroa (2005). In our case, the sources of uncertainty are the demand and the effective generation capacity, and therefore we introduce two additional parameters $\left(\phi^{D}(t), \phi^{C}(t)\right)$ : the time-dependent market price per unit of demand and capacity risk, respectively. Consequently, under the risk-neutral probability measure 2 the specification of the model is given by:

$$
\begin{aligned}
\ln P_{t} & =h(t)+\gamma \chi_{t}^{C}+\alpha \chi_{t}^{D} \\
\mathrm{~d} \chi_{t}^{D} & =-k^{D}\left(\chi_{t}^{D}+\theta^{D}(t)\right) \mathrm{d} t+\sigma_{D}(t) \mathrm{d} W_{t}^{D} \\
\mathrm{~d} \chi_{t}^{C} & =-k^{C}\left(\chi_{t}^{C}+\theta^{C}(t)\right) \mathrm{d} t+\sigma^{C} \mathrm{~d} W_{t}^{C}
\end{aligned}
$$

where $\mathrm{d} W_{t}^{D}$ and $\mathrm{d} W_{t}^{C}$ are the increments of two independent, standard Brownian motions, and

$$
\begin{aligned}
& \theta^{D}(t)=\frac{\phi^{D}(t) \sigma_{D}(t)}{k^{D}}, \\
& \theta^{C}(t)=\frac{\phi^{C}(t) \sigma^{C}}{k^{C}},
\end{aligned}
$$

\begin{tabular}{|c|c|c|c|c|c|c|}
\hline \multirow{2}{*}{ 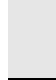 } & \multicolumn{2}{|l|}{ PJM } & \multicolumn{2}{|l|}{$\mathrm{E} \& W$} & \multicolumn{2}{|l|}{ Nord Pool } \\
\hline & Coefficient & $t$-stat & Coefficient & $t$-stat & Coefficient & $t$-stat \\
\hline$B_{0}$ & 3.2413 & 163.1605 & 2.6472 & 98.9554 & 3.3564 & 200.6536 \\
\hline$M_{2}$ & -0.0637 & -2.3174 & 0.0291 & 0.9603 & 0.0379 & 2.2305 \\
\hline$M_{3}$ & 0.0075 & 0.2786 & 0.0449 & 1.5170 & 0.1730 & 10.4027 \\
\hline$M_{4}$ & -0.0452 & -1.6687 & 0.1118 & 3.9278 & 0.1813 & 10.7993 \\
\hline$M_{5}$ & -0.1294 & -4.6273 & 0.1164 & 4.1190 & 0.0512 & 3.0833 \\
\hline$M_{6}$ & -0.1249 & -4.5751 & 0.0850 & 2.9768 & 0.1147 & 6.839 \\
\hline$M_{7}$ & 0.1098 & 4.0543 & 0.2373 & 8.3983 & 0.1494 & 8.9775 \\
\hline$M_{8}$ & 0.1062 & 3.9221 & 0.3709 & 13.1061 & 0.3098 & 18.6285 \\
\hline$M_{9}$ & -0.0932 & -3.3033 & 0.3583 & 12.5747 & 0.2138 & 13.3862 \\
\hline$M_{10}$ & -0.1252 & -4.5042 & 0.3384 & 11.9633 & 0.2005 & 12.6572 \\
\hline$M_{11}$ & -0.2077 & -7.4087 & 0.3469 & 12.1754 & 0.1695 & 10.6300 \\
\hline$M_{12}$ & -0.0404 & -1.4533 & 0.2915 & 10.2235 & 0.0551 & 3.4783 \\
\hline$Y_{1}$ & 0.3818 & 28.7939 & & & & \\
\hline$Y_{2}$ & 0.5460 & 23.9803 & -0.0833 & -4.3399 & & \\
\hline$Y_{3}$ & 0.5535 & 9.5811 & 0.0629 & 3.0118 & & \\
\hline$Y_{4}$ & 0.7940 & 47.6204 & 0.2538 & 11.9236 & -0.1352 & -10.5361 \\
\hline$Y_{5}$ & & & 0.9724 & 50.7857 & -0.1258 & -9.8002 \\
\hline$Y_{6}$ & & & & & 0.3617 & 28.1650 \\
\hline \multicolumn{7}{|l|}{$Y_{7}$} \\
\hline$\alpha$ & 0.0000380 & 34.5499 & 0.000014966 & 5.6122 & 0.000000752 & 17.4695 \\
\hline$\gamma$ & -0.0001486 & -3.9060 & -0.000043112 & -16.8483 & -0.006668338 & -13.0018 \\
\hline$R^{2}$ & 0.6196 & & 0.8021 & & 0.8235 & \\
\hline SSR & 248.2981 & & 46.6000 & & 15.4325 & \\
\hline
\end{tabular}

$h(t), \sigma^{D}(t), \sigma^{C}, k^{D}, k^{C}$ have the same interpretation as above.

Integrating Eqs. (15b) and (15c) over the time interval $(t, T)$ yields:

Table 4

Spot model and parameter estimates 


$$
\begin{aligned}
\ln P_{T}= & h(T) \\
& +\gamma\left(\mathrm{e}^{-k^{C}(T-t)} \chi_{t}^{C}+k^{C} \int_{t}^{T} \mathrm{e}^{-k^{C}(T-s)} \theta^{C}(s) \mathrm{d} s+\int_{t}^{T} \mathrm{e}^{-k^{C}(T-s)} \sigma^{C} \mathrm{~d} W_{s}^{C}\right) \\
& +\alpha\left(\mathrm{e}^{-k^{D}(T-t)} \chi_{t}^{D}+k^{D} \int_{t}^{T} \mathrm{e}^{-k^{D}(T-s)} \theta^{D}(s) \mathrm{d} s\right. \\
& \left.+\int_{t}^{T} \mathrm{e}^{-k^{D}(T-s)} \sigma_{D}(s) \mathrm{d} W_{s}^{D}\right),
\end{aligned}
$$

thus we can calculate the log-price of a forward contract at time $t$ delivering one MWh, at a pre-specified future date $T$,

$$
\begin{aligned}
\ln f(t, T)= & \ln \mathbb{E}_{t}^{2}\left[P_{T}\right] \\
= & h(T)+\gamma\left(\mathrm{e}^{-k^{C}(T-t)} \chi_{t}^{C}+k^{C} \int_{t}^{T} \mathrm{e}^{-k^{C}(T-s)} \theta^{C}(s) \mathrm{d} s\right. \\
& \left.+\frac{1}{2} \int_{t}^{T} \mathrm{e}^{-2 k^{C}(T-s)}\left(\sigma^{C}\right)^{2} \mathrm{~d} s\right) \\
& +\alpha\left(\mathrm{e}^{-k^{D}(T-t)} \chi_{t}^{D}+k^{D} \int_{t}^{T} \mathrm{e}^{-k^{D}(T-s)} \theta^{D}(s) \mathrm{d} s\right. \\
& \left.+\frac{1}{2} \int_{t}^{T} \mathrm{e}^{-2 k^{D}(T-s)} \sigma_{D}^{2}(s) \mathrm{d} s\right),
\end{aligned}
$$

where $\mathbb{E}_{t}^{2}$ is the expectation operator with respect to the risk-neutral measure 2 with information up until time $t$.

We may also write the price of the forward contract as the product of the expected price of power, under the physical measure $\mathscr{P}$, $\mathbb{E}_{t}^{\mathscr{P}}\left[P_{T}\right]$ and a correction factor that depends on the market prices of demand and capacity risk:

$f(t, T)=\exp \left[\gamma k^{C} \int_{t}^{T} \mathrm{e}^{-k^{C}(T-s)} \theta^{C}(s) \mathrm{d} s+\alpha k^{D} \int_{t}^{T} \mathrm{e}^{-k^{D}(T-s)} \theta^{D}(s) \mathrm{d} s\right] \mathbb{E}_{t}^{\mathscr{P}}\left[P_{T}\right]$.

Hence, the forward premium $F P(t, T)$, can be written as

$$
\begin{aligned}
F P(t, T)= & \mathbb{E}_{t}^{2}\left[P_{T}\right]-\mathbb{E}_{t}^{\mathscr{P}}\left[P_{T}\right]=f(t, T)-\mathbb{E}_{t}^{\mathscr{P}}\left[P_{T}\right] \\
= & \left(\operatorname { e x p } \left[\gamma k^{C} \int_{t}^{T} \mathrm{e}^{-k^{C}(T-s)} \theta^{C}(s) \mathrm{d} s\right.\right. \\
& \left.\left.+\alpha k^{D} \int_{t}^{T} \mathrm{e}^{-k^{D}(T-s)} \theta^{D}(s) \mathrm{d} s\right]-1\right) \mathbb{E}_{t}^{\mathscr{P}}\left[P_{T}\right],
\end{aligned}
$$

which also allows us to study the sign of the forward premium by looking at

$$
\begin{aligned}
& \operatorname{sign}\{F P(t, T)\} \\
& \quad=\operatorname{sign}\left\{\gamma k^{C} \int_{t}^{T} \mathrm{e}^{-k^{C}(T-s)} \theta^{C}(s) \mathrm{d} s+\alpha k^{D} \int_{t}^{T} \mathrm{e}^{-k^{D}(T-s)} \theta^{D}(s) \mathrm{d} s\right\} .
\end{aligned}
$$

One of the main advantages of our model is that we are able to express in an analytical way both the forward prices and the forward premiums. In commodities markets, and especially in power markets, understanding the behavior of the forward premium poses interesting challenges (see for example Benth et al. (in press)). One can focus attention on the forward bias itself (21), or focus on the question of whether forward prices are trading above (i.e. $F P(t, T)>0$ ) or below (i.e. $F P(t, T)<0$ ) the expected spot price. Thus, if we focus on the sign of the forward bias (22), we can see that the two key components that affect $F P(t, T)$ are the market prices of demand and capacity risk, which are in the functions $\theta^{D}(t)$ in (16) and $\theta^{C}(t)$ in (17). For example, if over the interval $(t, T)$ the market price of demand risk $\phi^{D}(s)<0$, then $\theta^{D}(s)<0$, in the same interval. This induces a downward pressure on the price of the forward $f(t, T)$, as can be seen from expression (20). Conversely, if over the interval $(t, T) \phi^{C}(s)>0$, then $\theta^{C}(s)>0$. This exerts a downward pressure on forward prices (recall that $\gamma<0$ ).
Other interesting results arise from considering how volatility of demand or volatility of capacity affects the forward premium. For example, if for simplicity we assume that $\gamma=0$ and that over a relevant time interval (for instance a season) the parameters $\phi^{D}(t), \sigma^{D}(t)$ are constant, then the size and sign of the forward premium only depend on the size and sign of $\theta^{D}(t)$. Furthermore, although the sign of $\theta^{D}(t)$ is determined by the sign of $\phi^{D}(t)$, it is not clear whether periods of high or low volatility of demand are accompanied by positive or negative $\phi^{D}(t)$.

According to Bessembinder and Lemmon (2002) the forward premium is decreasing in the variance of power prices and increasing in the skewness of power prices. In our model, although shocks to demand and capacity are symmetric, an increase in the volatility of demand or capacity increases both the variance and the skewness of power prices as a result of the convexity of the exponential function. Therefore during periods of high $\sigma^{D}(t)$ there would be two opposing forces acting on the forward premium $F P(t, T)$ and this is why we cannot unambiguously determine the sign of the term $\phi^{D}(t)$. A similar argument applies to the relationship between the sign of $\phi^{C}(t)$ and the size of $\sigma^{C}$.

\subsection{The forward premium}

The forward premium is an interesting quantity because it allows us to interpret how 'strong' hedging pressures from buyers and sellers of electricity are. For example, a positive forward premium indicates that forward contracts are trading at a premium over and above expected spot prices due to pressure from buyers. In our analysis we still need to estimate the risk-neutral parameters relating to the market prices of demand $\phi^{D}(t)$ and capacity $\phi^{C}(t)$ risk. ${ }^{9}$ For PJM, E\&W and Nord Pool we employ non-linear Least Squares to estimate $\phi^{D}(t)$ and $\phi^{C}(t)$ from monthly forwards, and since (19) is for delivery in one day, we use, as in Lucia and Schwartz (2002);

$F\left(t, T_{1}, T_{2}\right)=\frac{1}{T_{2}-T_{1}} \sum_{i=1}^{n} f\left(t, \tau_{i}\right) \quad T_{1}<T_{2}$,

where $T_{1}$ and $T_{2}$ are the start and finish of the delivery period, $n$ is the number of days between $T_{1}$ and $T_{2}$ and $f\left(t, \tau_{i}\right)$ is given by (19). Furthermore, partly due to: simplicity; the type of data we have as proxies for capacity; and the fact that we have assumed that the volatility of capacity is constant $\left(\sigma_{C}(t)=\sigma^{C}\right)$, we assume that the market price of capacity risk is constant, i.e. $\phi^{C}(t)=\phi^{C}$. However, on the other hand, we assume that the market price of demand risk is constant within the different seasons in the same way that we assumed that volatility of demand $\sigma^{D}(t)$ was also constant within seasons.

To estimate the market prices of risk we build on the results obtained from estimating the model under the physical measure. We use the deseasonalized demand and capacity series; the mean reversion coefficients $k^{D}$ and $k^{C}$; the (seasonal) volatility of demand $\sigma^{D}(t)$ and volatility of capacity $\sigma^{C}$ (all obtained in Sections 3.1 and 3.2); and $h(t), \alpha$ and $\gamma$ obtained in Section 4. The last step consists of estimating the market prices of capacity and demand risk. We estimate them by minimizing the sum of squared deviations between theoretical forward prices, given by (23), and daily quotes for monthly forwards in each market. Moreover, for each monthly contract we take observations of the price of the contract every day, until start of delivery, where the first price is that observed one month prior to the start of delivery. ${ }^{10}$

\footnotetext{
${ }^{9}$ The other parameters have already been estimated under the physical measure.

10 For example, for a forward delivering throughout the month of March, we use the forward price of the March contract for every day it was traded during the month of February.
} 
Table 5

PJM market prices of demand and capacity risk January 1999-March 2002, April 2002-August 2006, 1999, 2000

\begin{tabular}{|c|c|c|c|c|c|}
\hline & & Coefficient & Std. error & $t$-stat & Significance \\
\hline \multicolumn{6}{|c|}{ 1999-2002 $\phi^{D}(t)$} \\
\hline & Feb, March, April & 0.55164 & 0.16626 & 3.31785 & 0.00095 \\
\hline & Nov, Dec, Jan & 0.46548 & 0.16206 & 2.87221 & 0.00418 \\
\hline & May, June, July & 1.30065 & 0.08527 & 15.25191 & 0.00000 \\
\hline & Aug, Sep, Oct & 0.53861 & 0.16105 & 3.34431 & 0.00086 \\
\hline & $\phi^{C}$ & -2.24838 & 1.00732 & -2.23204 & 0.02587 \\
\hline & Adjusted $R^{2}$ & 0.60562 & & & \\
\hline & Mean square errors & 200.42 & & & \\
\hline \multirow[t]{8}{*}{ 2002-2006 } & $\phi^{D}(t)$ & & & & \\
\hline & Feb, March, April & 0.11636 & 0.07653 & 1.52049 & 0.12866 \\
\hline & Nov, Dec, Jan & 0.36663 & 0.07215 & 5.08171 & 0.00000 \\
\hline & May, June, July & -0.04187 & 0.04110 & -1.01878 & 0.30852 \\
\hline & Aug, Sep, Oct & 0.32195 & 0.07063 & 4.55837 & 0.00001 \\
\hline & $\phi^{C}$ & -3.92131 & 0.45467 & -8.62447 & 0.00000 \\
\hline & Adjusted $R^{2}$ & 0.53570 & & & \\
\hline & Mean square errors & 146.79 & & & \\
\hline \multirow[t]{8}{*}{1999} & $\phi^{D}(t)$ & & & & \\
\hline & Feb, March, April & 0.59546 & 0.22512 & 2.64510 & 0.00867 \\
\hline & Nov, Dec, Jan & 0.48079 & 0.22019 & 2.18353 & 0.02991 \\
\hline & May, June, July & 1.52356 & 0.11683 & 13.04116 & 0.00000 \\
\hline & Aug, Sep, Oct & 1.20182 & 0.20663 & 5.81619 & 0.00000 \\
\hline & $\phi^{C}$ & 2.85035 & 1.39951 & 2.03668 & 0.04271 \\
\hline & Adjusted $R^{2}$ & 0.84361 & & & \\
\hline & Mean square errors & 54.943 & & & \\
\hline \multirow[t]{8}{*}{2000} & $\phi^{D}(t)$ & & & & \\
\hline & Feb, March, April & 0.65748 & 0.38310 & 1.71622 & 0.08733 \\
\hline & Nov, Dec, Jan & 1.40370 & 0.35614 & 3.94145 & 0.00010 \\
\hline & May, June, July & 1.94386 & 0.19631 & 9.90191 & 0.00000 \\
\hline & Aug, Sep, Oct & 1.12011 & 0.35219 & 3.18041 & 0.00165 \\
\hline & $\phi^{C}$ & 0.69783 & 2.36838 & 0.29464 & 0.76850 \\
\hline & Adjusted $R^{2}$ & 0.77831 & & & \\
\hline & Mean square errors & 207.58 & & & \\
\hline
\end{tabular}

When estimating $\phi^{D}(t)$ and $\phi^{C}$ for different periods we keep all model parameters unchanged, but restrict the forward data to the particular periods we want to focus on.

Studies such as Bessembinder and Lemmon (2002); Pirrong and Jermakyan (1999, 2000) and Cartea and Villaplana (2008) present evidence for and discuss the existence of a seasonal pattern in the forward premium on the PJM. Our framework allows us to understand the different components that affect the seasonality, magnitude and sign of the forward premium. In our model the seasonal trends present in the volatility of demand $\sigma^{D}(t)$ and in the market price of demand risk $\phi^{D}(t)$, are the main drivers of the seasonal pattern exhibited by the forward premium (recall that we have market price of capacity risk is constant). The sign and magnitude of the forward premium on the other hand, are driven by the signs and magnitudes of $\phi^{D}(t), \phi^{C}$, $\sigma^{D}(t)$ and $\sigma^{C}$. Tables 5-7 show our parameter estimates for the market prices of risk in the PJM, E\&W and Nord Pool.

To study the market prices of risk in the PJM market, we split the data set into two sub-periods: 1999-2002; and 2002-2006. We do so to reflect a structural change in the PJM which partly resulted from its expansion to other territories, which commenced in 2002 (see FERC (2002)). Results for these two sub-periods can be seen in Table 5 . We find that the market price of capacity risk $\phi^{C}$ is statistically significant for the periods 2002-2006, where $\phi^{C}<0$, and the year 1999, where $\phi^{C}>0$. With regards to the market price of demand risk, there are three points to note. First, for both the periods, January 1999-March 2002 and April 2002-August 2006, the market prices of demand risk are statistically significant, with the exception of the months August, September and October in the sample April 2002-August 2006. Second, the signs of the statistically significant parameters $\phi^{D}(t)$ are positive in all cases. Third, the periods with largest market price of demand risk coincide with the periods of largest positive forward premium.
Table 6

E\&W market prices of demand and capacity risk 2001-2005, 2002, 2003, 2004, 2005

\begin{tabular}{|c|c|c|c|c|c|}
\hline & & Coefficient & Std. error & $t$-stat & Significance \\
\hline \multirow[t]{8}{*}{$2001-2005$} & $\phi^{D}(t)$ & & & & \\
\hline & Feb, March, April & 0.36433 & 0.47116 & 0.77327 & 0.43951 \\
\hline & Nov, Dec, Jan & 2.73326 & 0.33923 & 8.05738 & 0.00000 \\
\hline & May, June, July & -0.13266 & 0.72444 & -0.18312 & 0.85473 \\
\hline & Aug, Sep, Oct & 4.12213 & 0.42046 & 9.80374 & 0.00000 \\
\hline & $\phi^{C}$ & 0.53510 & 0.09341 & 5.72867 & 0.00000 \\
\hline & Adjusted $R^{2}$ & 0.83077 & & & \\
\hline & Mean square errors & 26.26 & & & \\
\hline \multirow[t]{8}{*}{2002} & $\phi^{D}(t)$ & & & & \\
\hline & Feb, March, April & -1.88930 & 0.77119 & -2.44986 & 0.01496 \\
\hline & Nov, Dec, Jan & 2.82391 & 0.52457 & 5.38331 & 0.00000 \\
\hline & May, June, July & -8.36588 & 1.21832 & -6.86671 & 0.00000 \\
\hline & Aug, Sep, Oct & -1.64332 & 0.68535 & -2.39780 & 0.01721 \\
\hline & $\phi^{C}$ & 1.64332 & 0.68535 & 2.39780 & 0.01721 \\
\hline & Adjusted $R^{2}$ & 0.46172 & & & \\
\hline & Mean square errors & 7.98 & & & \\
\hline \multirow[t]{8}{*}{2003} & $\phi^{D}(t)$ & & & & \\
\hline & Feb, March, April & -2.04081 & 0.90864 & -2.24599 & 0.02556 \\
\hline & Nov, Dec, Jan & 2.91950 & 0.61565 & 4.74211 & 0.00000 \\
\hline & May, June, July & -2.46126 & 1.34678 & -1.82752 & 0.06879 \\
\hline & Aug, Sep, Oct & 2.89532 & 0.77203 & 3.75026 & 0.00022 \\
\hline & $\phi^{C}$ & 0.06715 & 0.16956 & 0.39604 & 0.69241 \\
\hline & Adjusted $R^{2}$ & 0.65149 & & & \\
\hline & Mean square errors & 11.99 & & & \\
\hline \multirow[t]{8}{*}{2004} & $\phi^{D}(t)$ & & & & \\
\hline & Feb, March, April & 0.10659 & 0.52472 & 0.20313 & 0.83920 \\
\hline & Nov, Dec, Jan & 1.29704 & 0.38219 & 3.39373 & 0.00080 \\
\hline & May, June, July & 0.42891 & 0.80338 & 0.53389 & 0.59388 \\
\hline & Aug, Sep, Oct & 2.87404 & 0.47051 & 6.10837 & 0.00000 \\
\hline & $\phi^{C}$ & 0.01141 & 0.10324 & 0.11052 & 0.91208 \\
\hline & Adjusted $R^{2}$ & 0.72906 & & & \\
\hline & Mean square errors & 6.73 & & & \\
\hline \multirow[t]{8}{*}{2005} & $\phi^{D}(t)$ & & & & \\
\hline & Feb, March, April & 0.89137 & 0.95574 & 0.93266 & 0.35190 \\
\hline & Nov, Dec, Jan & 2.78877 & 0.69506 & 4.01231 & 0.00008 \\
\hline & May, June, July & 0.86419 & 1.47663 & 0.58525 & 0.55891 \\
\hline & Aug, Sep, Oct & 5.87490 & 0.85131 & 6.90103 & 0.00000 \\
\hline & $\phi^{C}$ & 0.87961 & 0.19019 & 4.62484 & 0.00001 \\
\hline & Adjusted $R^{2}$ & 0.68631 & & & \\
\hline & Mean square errors & 57.43 & & & \\
\hline
\end{tabular}

When estimating $\phi^{D}(t)$ and $\phi^{C}$ for different periods we keep all model parameters unchanged, but restrict the forward data to the particular periods we want to focus on.

In the three markets we study, our empirical findings indicate that the forward premium is higher in those contracts that mature in periods of high volatility of demand. To calculate the forward premium we take the difference between forward prices, obtained from the fitted model, and expected spot price based on the parameter estimates derived above. For example, from Table 2 we can verify that the months with the highest volatility of demand in the PJM market are June, July and August and those with the second highest volatility value are September, October and November. Moreover, in PJM during the sub-period 1999-2002 we can see that the months of May, June and July, ${ }^{11}$ (which exhibit the largest forward premium ranging between $\$ 30$ and $\$ 75$ as shown in Fig. 10) coincide with the months where we found that the volatility of demand was highest and the market price of demand risk was also highest and Fig. 11 shows the PJM forward premium for the period 2002-2006. ${ }^{12}$

In PJM we also observe that the forward premium is negative during the months of January, February, November and December in 1999. In this year $\phi^{C}>0$ and hence the market price of capacity

\footnotetext{
11 We remark that the period with high volatility of demand aligns with that of high forward premium because we are looking at monthly forwards that trade in May, June and July, but with delivery period in June, July and August.

12 When we look at particular years or subsets of the data to estimate the market prices of risk and capacity, we do not re-estimate the other parameters of the model.
} 
Table 7

Nord Pool market prices of demand and capacity risk 2003-2006, 2004, 2005, 2006

\begin{tabular}{|c|c|c|c|c|c|}
\hline & & Coefficient & Std. error & $t$-stat & Significance \\
\hline \multirow[t]{8}{*}{ 2003-2006 } & $\phi^{D}(t)$ & & & & \\
\hline & Feb, March, April & 0.89836 & 0.11114 & 8.08325 & 0.00000 \\
\hline & Nov, Dec, Jan & 1.24279 & 0.09926 & 12.51998 & 0.00000 \\
\hline & May, June, July & 0.64019 & 0.14490 & 4.41825 & 0.00001 \\
\hline & Aug, Sep, Oct & 1.47927 & 0.10416 & 14.20239 & 0.00000 \\
\hline & $\phi^{C}$ & 0.50350 & 0.07246 & 6.94839 & 0.00000 \\
\hline & Adjusted $R^{2}$ & 0.80494 & & & \\
\hline & Mean square errors & 24.76 & & & \\
\hline \multirow[t]{8}{*}{2004} & $\phi^{D}(t)$ & & & & \\
\hline & Feb, March, April & 0.50788 & 0.08984 & 5.65321 & 0.00000 \\
\hline & Nov, Dec, Jan & 1.05481 & 0.08043 & 13.11525 & 0.00000 \\
\hline & May, June, July & 0.72267 & 0.11480 & 6.29509 & 0.00000 \\
\hline & Aug, Sep, Oct & 0.66691 & 0.08588 & 7.76537 & 0.00000 \\
\hline & $\phi^{C}$ & 0.37751 & 0.05749 & 6.56696 & 0.00000 \\
\hline & Adjusted $R^{2}$ & 0.12273 & & & \\
\hline & Mean square errors & 3.51 & & & \\
\hline \multirow[t]{8}{*}{2005} & $\phi^{D}(t)$ & & & & \\
\hline & Feb, March, April & 1.33298 & 0.24407 & 5.46135 & 0.00000 \\
\hline & Nov, Dec, Jan & 2.35596 & 0.21745 & 10.83446 & 0.00000 \\
\hline & May, June, July & 1.62829 & 0.31741 & 5.12995 & 0.00000 \\
\hline & Aug, Sep, Oct & 1.88832 & 0.23401 & 8.06941 & 0.00000 \\
\hline & $\phi^{C}$ & 1.01548 & 0.16274 & 6.23977 & 0.00000 \\
\hline & Adjusted $R^{2}$ & 0.26811 & & & \\
\hline & Mean square errors & 20.21 & & & \\
\hline \multirow[t]{8}{*}{2006} & $\phi^{D}(t)$ & & & & \\
\hline & Feb, March, April & 0.89782 & 0.12698 & 7.07055 & 0.00000 \\
\hline & Nov, Dec, Jan & 0.62746 & 0.11828 & 5.30476 & 0.00000 \\
\hline & May, June, July & 0.26146 & 0.16710 & 1.56474 & 0.11888 \\
\hline & Aug, Sep, Oct & 1.78522 & 0.11907 & 14.99295 & 0.00000 \\
\hline & $\phi^{C}$ & 0.37236 & 0.08267 & 4.50431 & 0.00001 \\
\hline & Adjusted $R^{2}$ & 0.80375 & & & \\
\hline & Mean square errors & 19.46 & & & \\
\hline
\end{tabular}

When estimating $\phi^{D}(t)$ and $\phi^{C}$ for different periods we keep all model parameters unchanged, but restrict the forward data to the particular periods we want to focus on.

risk exerts a downward pressure, whilst the market price of demand risk applies an upward pressure, on the forward prices. It is during the months where volatility of demand is relatively low that we see a downward pressure due to capacity risk outweighing the effects of a positive market price of demand risk. This results in a negative forward premium. We provide an intuitive explanation of the negative forward premium in two steps. First, since during months of low volatility of demand the probability of observing price spikes is relatively low, buyers have fewer incentives to cover their positions by purchasing power forward, but sellers still prefer to sell forward contracts to reduce variability in their profits. This reasoning applies at all times when the volatility of demand is low, but does not imply that the forward premium must be negative, it only implies that the contribution to the forward premium due to demand risk and price spikes is not too large during periods of low demand and low volatility of demand.

The second leg of the argument is based on the fact that sellers face variability of power prices due to unexpected changes in the total generation capacity of the system. Positive capacity shocks reduce power prices and negative shocks increase power prices. During times of low demand and low volatility of demand, it is less likely to see price spikes as a result of a fall in capacity. Hence, although sellers would like to take advantage of possible price spikes, due to negative capacity shocks, by selling spot rather than forward, their fear of price falls, due to unexpected positive movements in the total generation capacity, provides a much stronger incentive to sell forward contracts. Hence, this willingness to hedge risks, induced by random deviations in capacity, drives forward prices down. In some circumstances, this downward pressure is strong enough to drive discounts up to the extent that expected spot prices are higher than forward prices (thus generating a negative forward premium) (see Fig. 12).

We can compare our results for the years 1999 and 2000 with those of Bessembinder and Lemmon (2002), where our findings are broadly in agreement (signs and magnitudes). From Figs. 12 and 13 we can observe that the lowest forward premium occurs between the months of January to May and September to December.

Similarly, we can interpret the results for the E\&W market. In Table 6 we present the estimation results for the market prices of demand and capacity risk. We employ forward contracts data from April 2001 to December 2005 and present results for the whole series and for the years 2002, 2003, 2004 and 2005. For the entire data set we see that $\phi^{C}$ is positive and statistically significant and that the largest $\phi^{D}(t)$ are those encompassing the months August through January. During these months, a large positive market price of demand risk is also accompanied by a period of high volatility of demand. The combined effect of a large positive $\phi^{D}(t)$ and large $\sigma^{D}(t)$ exerts an upward pressure on the monthly forward contracts trading in the months August through January, with delivery in September through February. Consequently,

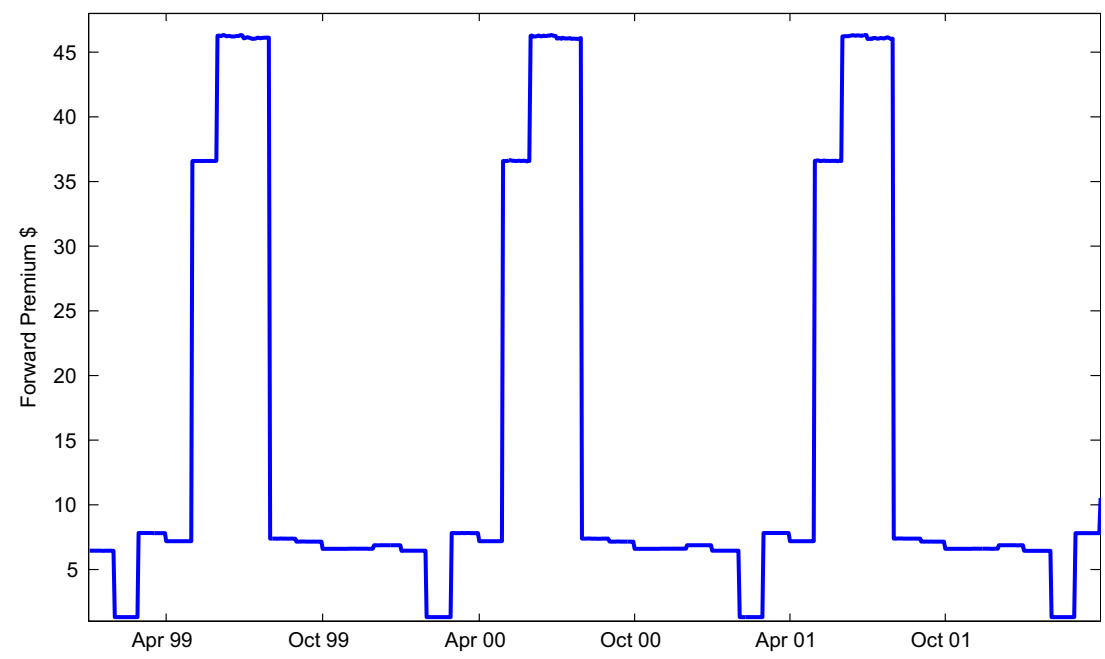

Fig. 10. PJM forward premium January 1999-April 02. 


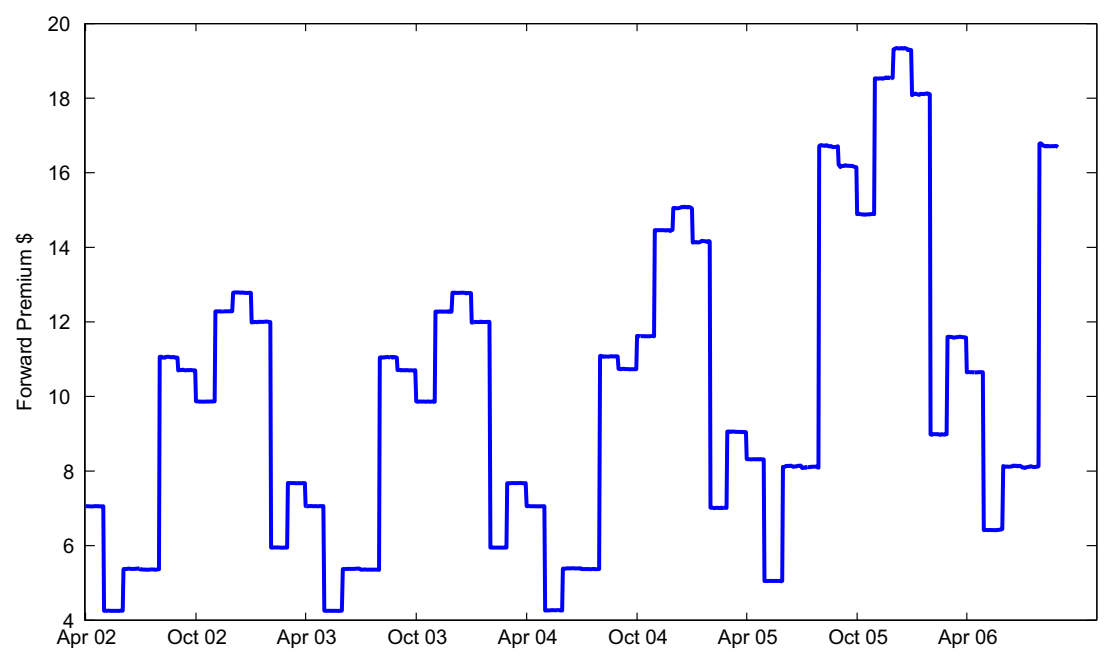

Fig. 11. PJM forward premium 2002-2006.

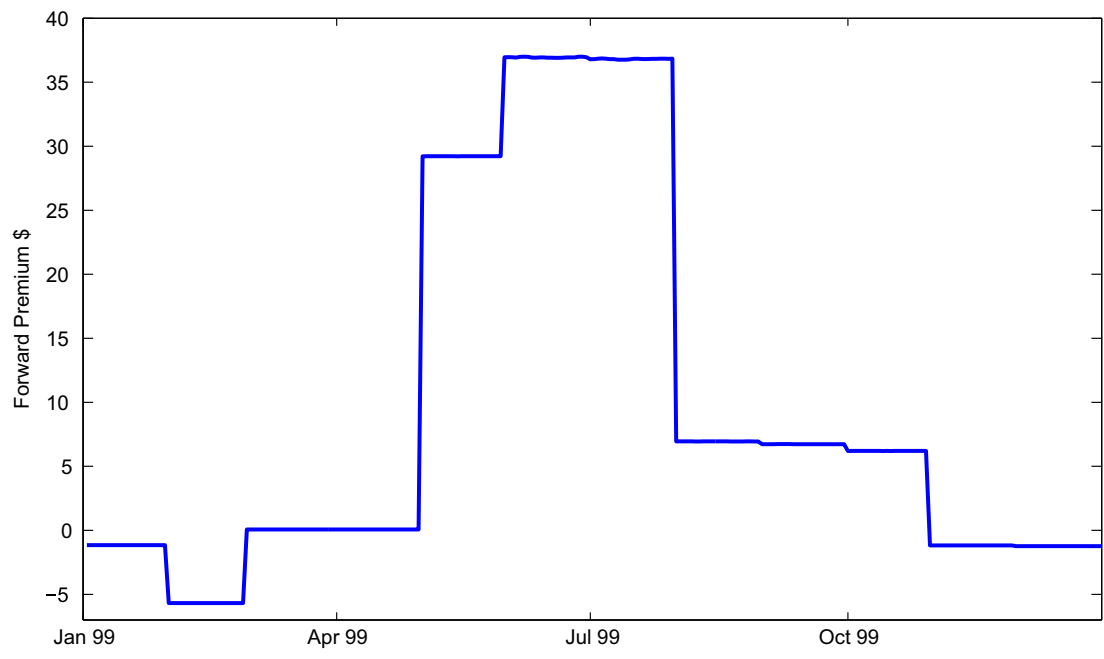

Fig. 12. PJM forward premium 1999.

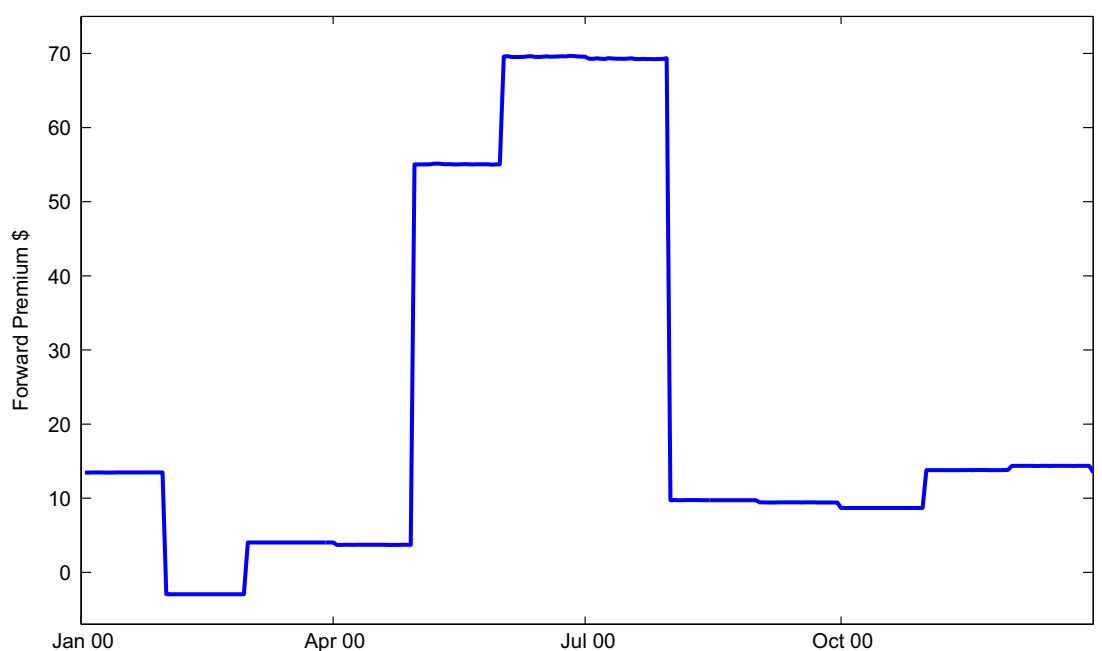

Fig. 13. PJM forward premium 2000. 


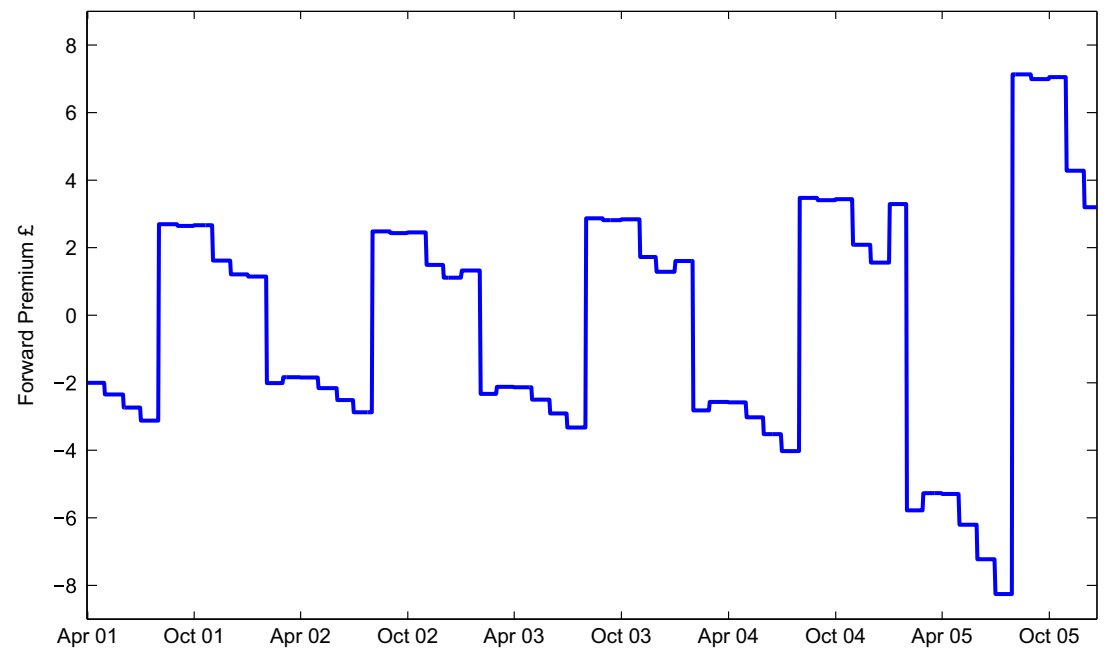

Fig. 14. E\&W forward premium April 2001-December 05.

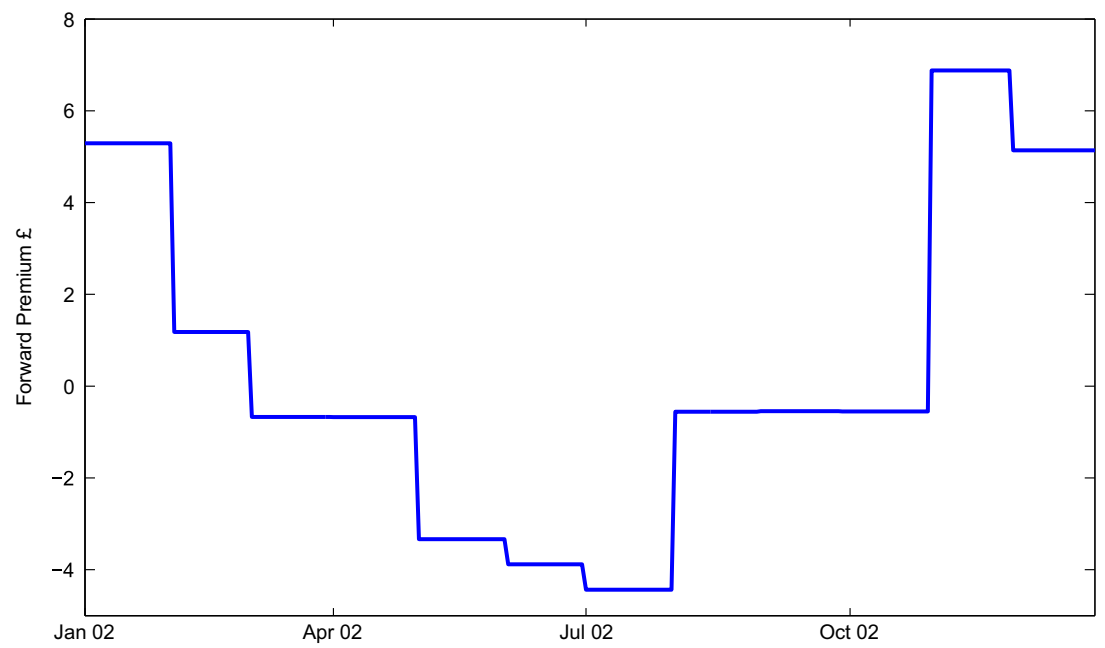

Fig. 15. E\&W forward premium 2002.

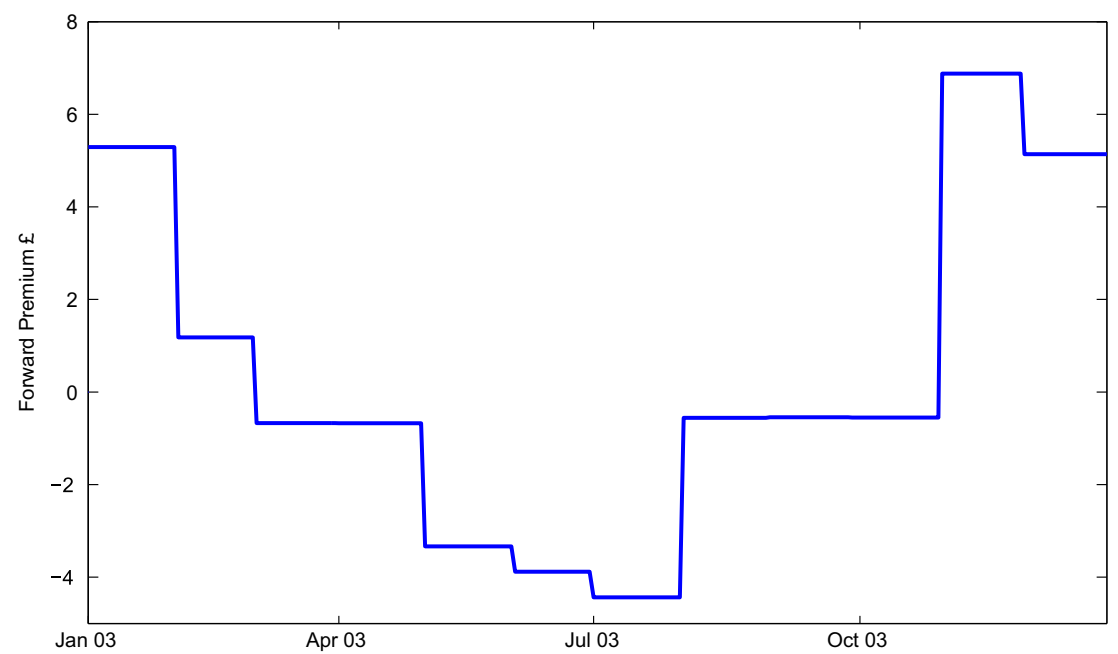

Fig. 16. E\&W forward premium 2003. 


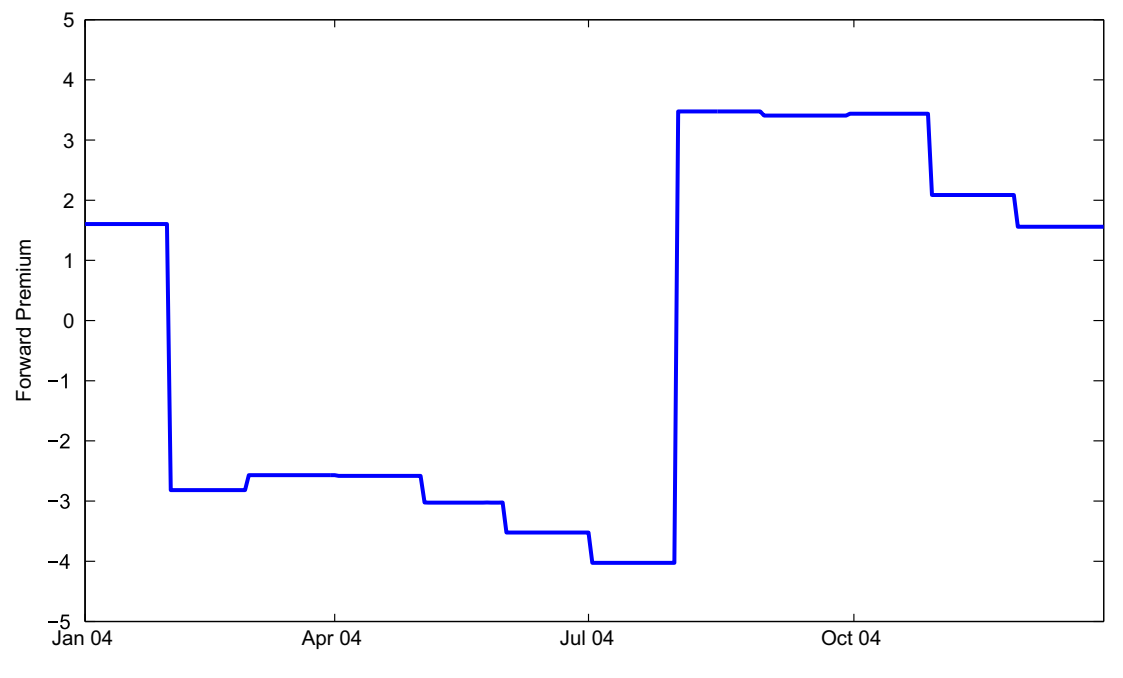

Fig. 17. E\&W forward premium 2004.

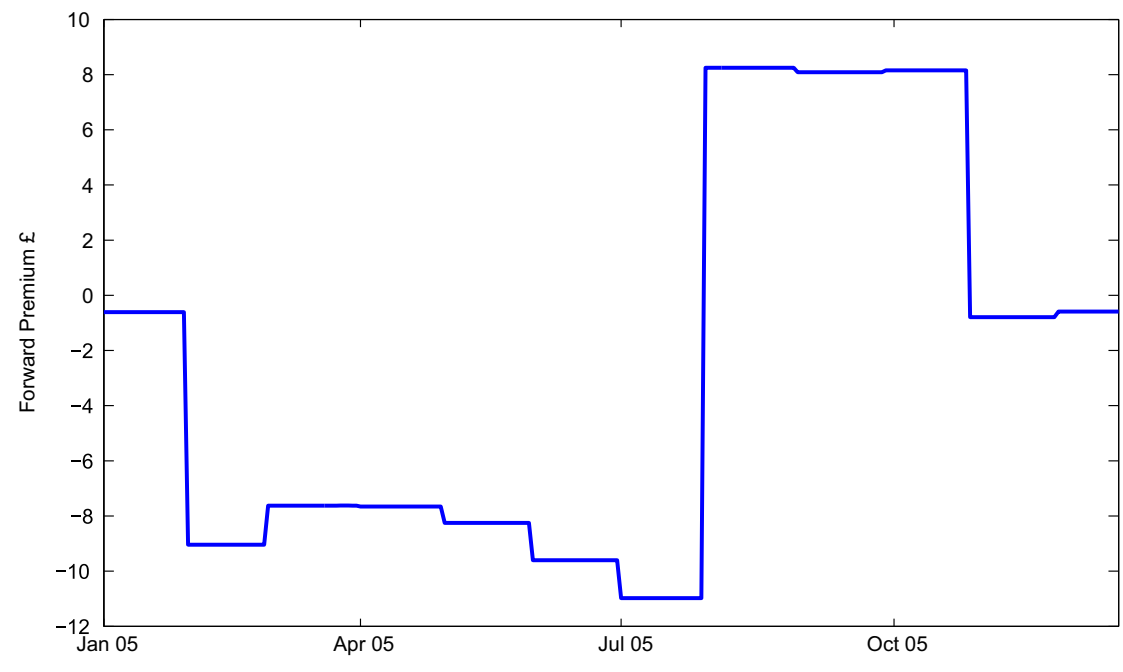

Fig. 18. E\&W forward premium 2005.

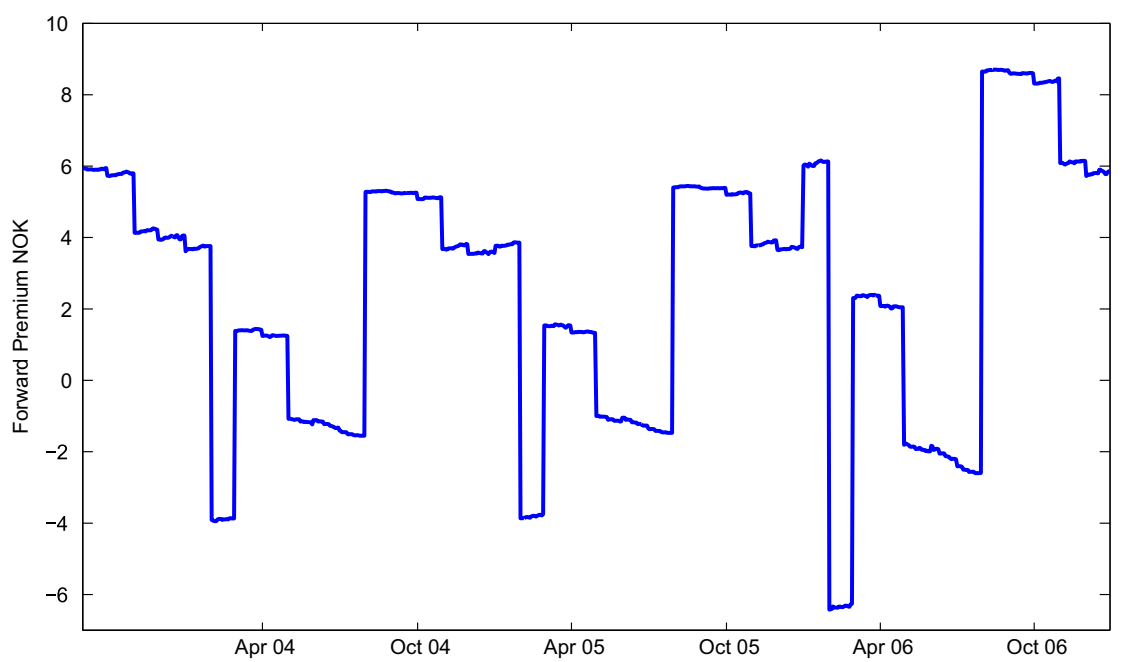

Fig. 19. Nord Pool forward premium September 2003-December 2006. 


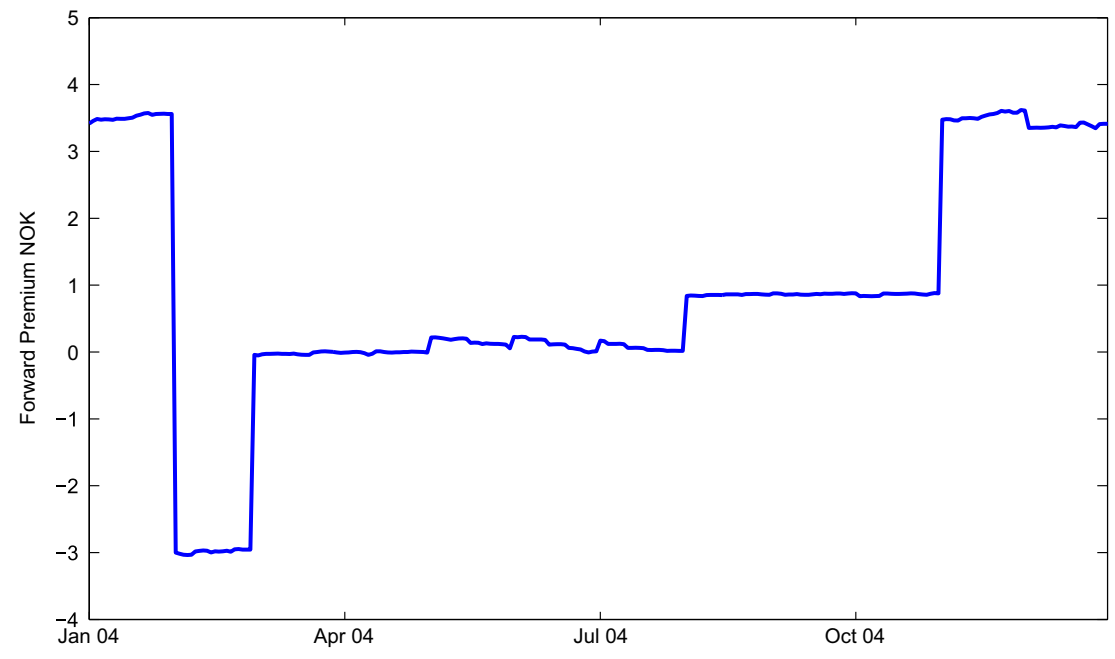

Fig. 20. Nord Pool forward premium 2004.

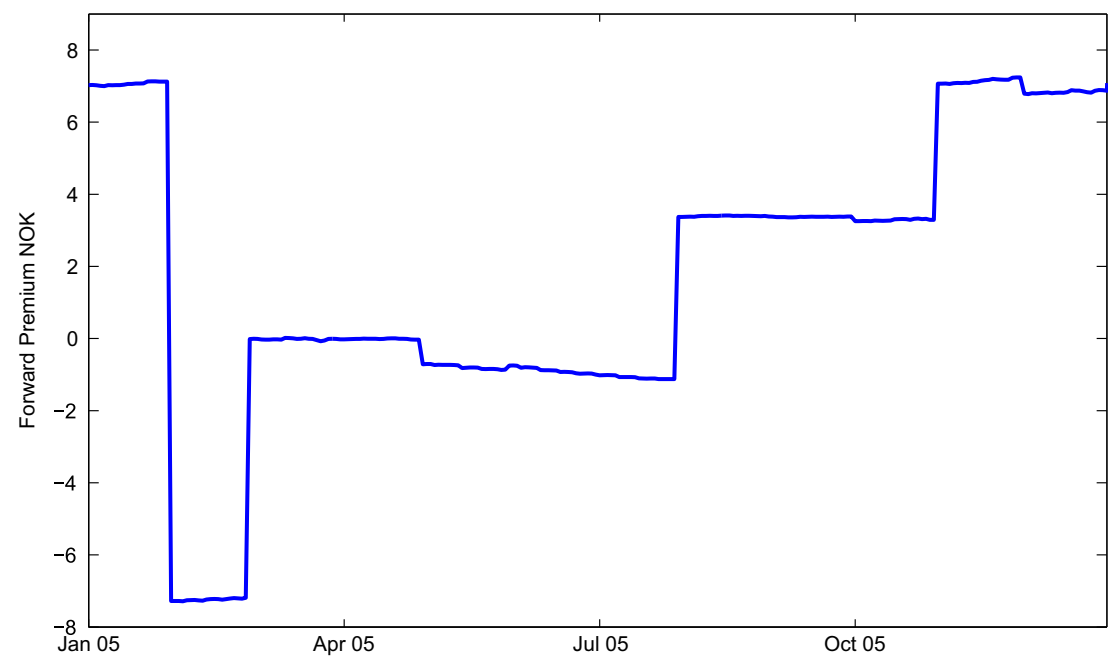

Fig. 21. Nord Pool forward premium 2005.

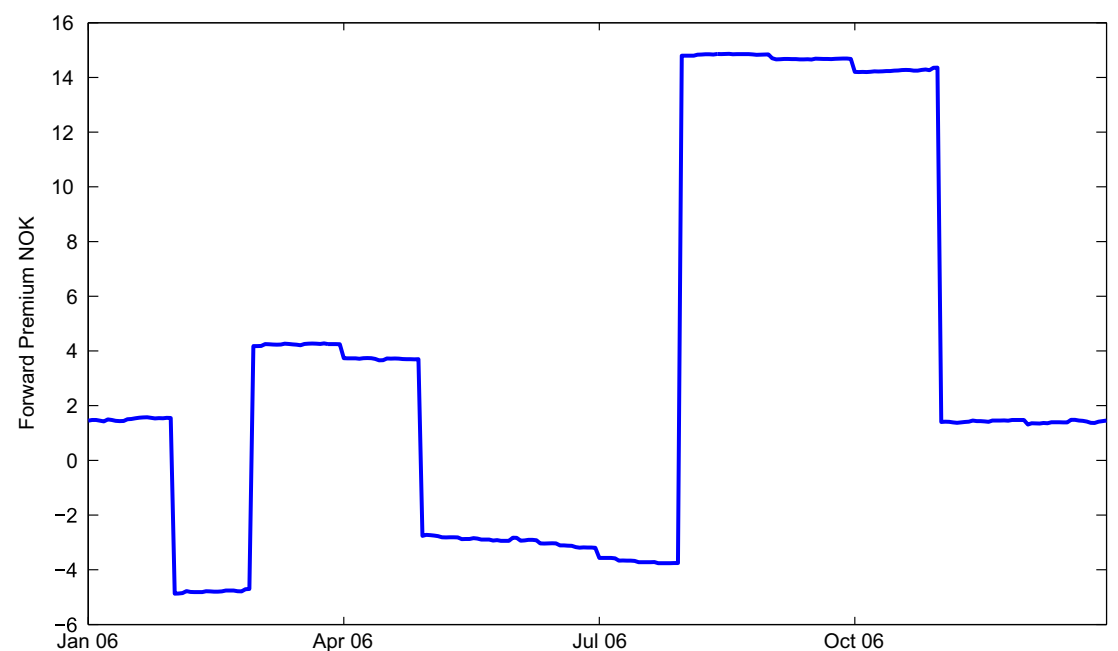

Fig. 22. Nord Pool forward premium 2006 
monthly forward contracts trade significantly above the expected prices of electricity; in other words, there is a substantial forward premium during these months.

Fig. 14 depicts the forward premium in $\mathrm{E} \& \mathrm{~W}$ for the period April 2001 to December 2005. We observe that this premium is highest between August and January of each year, ranging between $£ 2$ and $£ 9$ per $\mathrm{MWh}$, and that it also follows a seasonal pattern (due mainly to the seasonality of the volatility of demand). On the other hand, during the rest of the year, forward contracts trade at a considerable discount, as revealed by a forward premium ranging between $£-2$ and $£-9$ per $M W h$. We can interpret this negative forward premium in the same way as in the PJM. Moreover, Figs. 15-18 show the forward premium for 2002, 2003, 2004 and 2005.

Finally, Table 7 presents the market prices of demand and capacity risk for the Nord Pool market. We focus on the period 2003-2006 and also look at the years 2004, 2005 and 2006. In all cases the market prices of capacity and demand risk are statistically significant. Over the period 2003-2006 we observe that the months with negative $F P(t, T)$ are February, May, June and July; the latter three months coinciding with the periods of lowest volatility of demand. See Figs. 19-22 where we depict the forward premium for the whole sample 2003-2006 and for the years 2004, 2005 and 2006.

\section{Conclusions}

The main objective of this article is to propose an electricity price model that allows us to: understand the behavior of spot prices; understand the connection between power prices and forward contracts; and investigate the dynamics of the forward premium, defined as the difference between forward prices and expected power prices.

We assume that wholesale electricity prices can be explained by two state variables: demand and capacity. We model these two variables, and their relationship with power prices, by employing data from three different markets: PJM, E\&W and Nord Pool. One of the key requirements we impose on the model is that it must be able to express, in an analytical way, expected spot prices and the price of forward contracts. This allows us to express the forward premium in closed-form.

We highlight five of our findings. First, in all markets, demand or load follows a strong seasonal component and a demand model with seasonal or time-varying volatility is preferred to one with constant volatility.

Second, in all markets, monthly forward contracts trade at a higher premium during months of high volatility of demand. We saw that in PJM the months that showed the highest volatility of demand also exhibited the largest forward premium. Our calculations of the forward premium for the individual years of 1999 and 2000 are similar to those obtained by Bessembinder and Lemmon (2002) and can reach levels ranging between $\$ 30$ and $\$ 75$ during periods of high volatility of demand in May, June and July.

Third, in all markets, we found that in the majority of the cases when data from monthly forwards were employed, months with high volatility of demand were accompanied with statistically significant positive $\phi^{D}(t)$.

Fourth, we also observed in all markets that the forward premium dynamics are seasonal. It is interesting to note that in PJM, for the years 1999 and 2000, there are periods where the forward premium achieves negative values. Similarly, in the E\&W market we saw that during the months of February to July in 2002-2005 the monthly forward contracts traded below the expected spot price of power, a situation also present in the Nord Pool during the months of February, April, May June and July during the period
2003-2006. The intuition behind this result is that during the periods of negative forward premium, monthly forwards trade at a large discount due to hedging pressure from sellers. Likewise, during the months between August and January, forward contracts in $\mathrm{E} \& \mathrm{~W}$ were trading at a high premium, indicating hedging pressures from buyers in this market.

Finally, our findings indicate that the market price of capacity risk could be either positive or negative depending on the market and period under study. For example, over the period 20012005 , we found that in E\&W $\phi^{C}>0$, and over the period 20032006 we found that in Nord Pool $\phi^{C}>0$, which applied a downward pressure on the price of forward contracts. This pressure reflected sellers' willingness to offer forward contracts at a considerable discount, especially during the months of February to July in E\&W and during the months of February to July, with the exception of March, in Nord Pool. In these months, forward contracts traded below the expected spot price as revealed by a forward premium ranging between $£-2$ and $£-9$ per $\mathrm{MWh}$ in $\mathrm{E} \& \mathrm{~W}$ and between NOK-1 and NOK-7 per MWh in Nord Pool. The intuition behind this result is that during months of relatively low volatility of demand, shocks to the supply side become more relevant to sellers who want to hedge the unwanted outcome of price falls that result from unexpected positive shocks to generation capacity.

\section{Acknowledgement}

We have benefited from the helpful comments of Richard Green, Craig Pirrong, Steen Koekebakker, Ignacio Peña, Vicente Meneu, Julio Lucía, Gareth Davies, Murray Hartley, Andrew Shaw, Peter E. George, James Cheeseman, Eric Tjøtta, seminar attendants and conference participants at Pompeu Fabra, University of Valencia, II Commodities Modelling Workshop (University of ULM) and ASSA meeting (Philadelphia). All remaining errors are our sole responsibility. We are also very grateful to Shanti Majithia and Richard Price at the National Grid Company and Oxera Consulting for providing data.

\section{References}

Barlow, M.T., 2002. A diffusion model for electricity prices. Mathematical Finance 12, 287-298.

Benth, F.E., Cartea, Á., Kiesel, R., in press. Pricing Forward Contracts in Power Markets by the Certainty Equivalence Principle: explaining the sign of the market risk premium. Journal of Banking and Finance. doi:10.1016/ j.jbankfin.2007.12.022.

Bessembinder, H., Lemmon, M.L., 2002. Equilibrium pricing and optimal hedging in electricity forward markets. Journal of Finance LVII, 1347-1382.

Cartea, Á., Figueroa, M.G., 2005. Pricing in electricity markets: a mean reverting jump diffusion model with seasonality. Applied Mathematical Finance 12, 313335.

Cartea, Á., Figueroa, M.G., Geman, H., 2007. Modelling Electricity Prices with Forward Looking Capacity Constraints. Working Paper.

Cartea, Á., Villaplana, P., 2008. Pricing power derivatives: a two-factor jumpdiffusion approach. Working Paper.

FERC, 2002, PJM Electric Market: Overview and Focal Points, www.ferc.gov, Federal Energy Regulatory Commission.

Geman, H., Eydeland, A., 1998. Pricing power derivatives. Risk.

Geman, H., Roncoroni, A., 2006. Understanding the fine structure of electricity prices. Journal of Business 79, 1225-1261.

Kollberg, J., Elf, J., Wigert, P., Lundquist, F., Mork, E., Cho, A., 1999. Energy Modelling and the Management of Uncertainty. Risk Publications.

Krapels, E.N., 2000. Electricity Trading and Hedging. Risk Publications.

Longstaff, F.A., Wang, A.W., 2004. Electricity forward prices: a high-frequency empirical analysis. Journal of Finance LIX, 1877-1900.

Lucia, J., Schwartz, E.S., 2002. Electricity prices and power derivatives: evidence from the nordic power exchange. Review of Derivatives Research 5, 5-50.

Melino, A., 1994. Advances in Econometrics. chap. Estimation of Continuous-time Models in Finance, vol. 2. Cambridge University Press.

Pardo, A., Meneu, V., Valor, E., 2002. Temperature and seasonality influences on Spanish electricity load. Energy Economics 24, 55-70.

Pirrong C. Jermakyan, M. 1999. Valuing power and weather derivatives on a mesh using finite difference methods. Energy Modelling and the Management of Uncertainty, Risk Publications. 
Pirrong, C., Jermakyan, M., 2000, The price of power: the valuation of power and weather derivatives, Working Paper, Olin School of Business, Washington University.

Schwartz, E.S., 1997. The stochastic behavior of commodity prices: implications for valuation and hedging. Journal of Finance 52, 923-973.

Schwartz, E.S., Smith, J.E., 2000. Short-term variations and long-term dynamics in commodity prices. Management Science 46, 893-911.
Skantze, P., A. Gubina, M. Ilic, 2000, Bid-based stochastic model for electricity prices: the impact of fundamental drivers on market dynamics, Report 00-04, Energy Laboratory, MIT.

Skantze, P., Ilic, M.D., 2001. Valuation, Hedging and Speculation in Competitive Electricity Markets: A Fundamental Approach. Kluwer Academic Publishers. 